\title{
LAS ORDENACIONES FORESTALES EN LAS PRIMERAS DÉCADAS DEL SIGLO XX: CAMBIO INSTITUCIONAL Y RESULTADOS PRODUCTIVOS*
}

\author{
IÑAKI IRIARTE GOÑI \\ Universidad de Zaragoza ${ }^{\mathrm{a}}$
}

\begin{abstract}
RESUMEN
El trabajo analiza las ordenaciones de montes de principios del siglo XX en España para evaluar en qué medida se lograron alcanzar los objetivos para los que fueron planteadas. Para ello se enmarcan las ordenaciones en el conjunto de la política forestal, se profundiza en el proceso de concesiones de ordenación a particulares y se analizan las principales normas de explotación estipuladas en los contratos. La principal conclusión es que las normas concretas que regularon las ordenaciones presentaron deficiencias que no permitieron cumplir plenamente los objetivos: si bien se logró acelerar las extracciones forestales en momentos determinados, no se consiguió un incremento sostenido de la productividad y hay sospechas de que todo ello pudo incidir negativamente sobre las existencias forestales de los montes sujetos a ordenación.
\end{abstract}

Palabras clave: economía forestal, política forestal, historia forestal, montes públicos.

\footnotetext{
${ }^{*}$ Este trabajo cuenta con la financiación de un proyecto de Investigación del Rectorado de la Universidad de Zaragoza (269-31). Agradezco a José Ignacio Jiménez Blanco y a Santiago Zapata Blanco la atenta lectura que realizaron de una versión preliminar y los consejos que me dieron. Agradezco también las sugerencias de los evaluadores anónimos y del Comité Editorial de la Revista de Historia Económica, que han contribuido a mejorar el trabajo. Los errores que puedan subsistir son, por supuesto, de mi exclusiva responsabilidad.

a Departamento de Estructura e Historia Económica y Economía Pública, Facultad de Ciencias Económicas y Empresariales, Gran Vía, 2, 50005, Zaragoza. iiriarte@unizar.es
} 


\begin{abstract}
This work explores the management of public forests in Spain at the beginning of the twentieth century, in an effort to evaluate its effectiveness. For this purpose the article examine why and how the State made public forest management concessions to private enterprise, and analyzes the specific clauses of the contracts. The main conclusion is that those clauses were inefficient and although they accelerated forest product extractions, they did not achieve a constant growth of forest productivity. This could have had a negative effect on the sustainability of the forests being managed.
\end{abstract}

Keywords: forestry, government policy.

JEL Classification: N53, Q23, Q28.

\title{
1. INTRODUCCIÓN
}

Como es bien sabido, durante las primeras décadas del siglo XX la economía española atravesó por un periodo de profundas transformaciones que modificaron la importancia y las formas de operar de muchos sectores económicos. Entre ellos, el sector forestal en sus múltiples variantes se vio afectado por cambios significativos que se pueden relacionar con el desarrollo de numerosas actividades que utilizaban madera, resina o corcho como materia prima. El incremento de la demanda de algunos de esos productos se cubrió, en parte, con unas importaciones forestales que crecieron considerablemente (en especial las de madera) a pesar del marco proteccionista predominante durante el periodo ${ }^{1}$. Pero paralelamente se produjo también un crecimiento de la producción forestal interior que registró un incrementó superior al del sector agrario en su conjunto y que afectó tanto a los montes privados como a los públicos del país ${ }^{2}$. En lo que se refiere a estos últimos (los únicos para los que existen datos de producción sistemáticos

${ }^{1}$ Véase Gallego y Pinilla (1996) y Iriarte Goñi (2005).

${ }^{2}$ Véase Jiménez Blanco (2002). Como señala Tortella (1994) los montes españoles han representado históricamente una fracción muy pequeña de la renta agraria del país, y aunque esa afirmación es cierta también para el primer tercio del siglo XX, el crecimiento del producto forestal que se produjo en ese periodo fue muy importante. Desde el punto de vista extractivo, los trabajos de Zapata (2001) para la madera, de Zapata (1986) y Sala (1997) para el corcho o de Uriarte (1994) para la resina, dan buena muestra de ello. Desde la perspectiva de la transformación industrial de esos productos, las cifras aportadas por Nadal (1987), Prados de la Escosura (1988) y Garrués, Hernández y Martín (2003) sobre el sector de la madera, las de Zapata (1996) y Sala (1998) sobre la industria corchera, o las de Uriarte (1998) para la industria resinera dan muestras también del dinamismo del sector. 
sobre ese periodo a escala nacional), los trabajos que recientemente han analizado su evolución en perspectiva histórica explican el incremento del producto que se detecta en ellos aludiendo a la importancia de las ordenaciones forestales que el Estado impulsó desde finales del siglo XIX y afirman que las mismas supusieron un incremento de la productividad forestal ${ }^{3}$. Paralelamente, esos mismos autores, así como algunos otros que han abordado el tema de la política forestal del periodo señalan que la práctica totalidad de esas ordenaciones fueron llevadas a cabo por empresas privadas que gestionaron los montes ordenados en beneficio propio obteniendo enormes ganancias a través de esas operaciones ${ }^{4}$. Ambos planteamientos no son necesariamente incompatibles, pero la doble valoración que implícitamente realizan, invita a profundizar en el desarrollo de un proceso que hasta el momento sólo ha sido abordado de manera superficial, que afectó a una cantidad no desdeñable de montes, que supuso una innovación organizativa importante en la gestión de esos espacios y que permite, por todo ello, adentrarse en el complejo tema del cambio institucional y de sus efectos productivos, relacionándolo con el comportamiento de los diversos agentes implicados en él.

Teóricamente, las ordenaciones puestas en marcha en España desde finales del siglo XIX pretendían incrementar la producción forestal a través de una intervención institucional que garantizara al mismo tiempo la conservación de los montes. Pero para saber si ese doble objetivo se cumplió parece necesario indagar en el desarrollo de esas operaciones tratando de contestar a cuatro grupos de preguntas. En primer lugar, ¿qué papel desempeñaron las ordenaciones en el conjunto de la política forestal española? y ¿por qué se recurrió a la iniciativa privada para llevarlas a cabo? ¿Existían otras alternativas para cumplir los objetivos planteados? En segundo lugar, ¿qué criterios se siguieron para efectuar las concesiones a particulares? ¿Se trató de un proceso que contribuyó a incrementar la eficiencia en las formas de gestión? En tercer lugar, ¿cuáles fueron las condiciones de explotación que se fijaron en los contratos? ¿Fueron adecuadas para conseguir los objetivos perseguidos o generaron disfunciones que trabaron un desarrollo más satisfactorio? Finalmente, ¿cómo influyeron las normas arbitradas en la producción de los montes ordenados? ¿Puede hablarse en realidad de un incremento sostenido de la productividad? Y ¿se consiguió realmente cubrir el objetivo de conservar las existencias forestales previas al cambio en la gestión?

Para ir dando respuesta a esas cuestiones, en este trabajo se manejan dos herramientas complementarias. De un lado, se utilizan las Estadísticas de la Producción de los Montes de Utilidad Pública Españoles, que para el periodo comprendido entre 1901 y 1933 aportan información abundante sobre los montes ordenados y permiten aproximarse a algunos de los principales resultados de las ordenaciones a

\footnotetext{
${ }^{3}$ Véase Zapata (2001) y GEHR (2002).

${ }^{4}$ Sanz Fernández (1986), Gómez Mendoza (1992) y GEHR (1994).
} 
escala nacional ${ }^{5}$. De otro, teniendo en cuenta que el desarrollo de esas operaciones fue bastante complejo y que no se ha localizado información sistemática a escala nacional sobre las concesiones y sobre los empresarios implicados, se aborda en profundidad el caso de una provincia concreta (Teruel) que, junto a algunos datos complementarios sobre lo ocurrido en otras zonas, permite seguir los pormenores del proceso de adjudicación y profundizar en las condiciones de explotación establecidas en los contratos, así como calibrar algunas de sus consecuencias ${ }^{6}$.

Después de esta breve introducción, el trabajo se divide en cuatro secciones que tratan de contestar a cada uno de los cuatro grupos de preguntas señalados más arriba, y finaliza con unas conclusiones en las que se sintetizan las respuestas obtenidas a las mismas.

\section{LAS ORDENACIONES FORESTALES EN EL CONTEXTO DE LA POLÍTICA FORESTAL}

Teniendo en cuenta que las ordenaciones forestales constituyeron tan sólo una de las formas de actuación del Estado respecto a los montes, parece necesario explicar, en primer lugar, cuándo, por qué y con qué criterios generales se pusieron en marcha, tomando en consideración otras alternativas posibles. En este sentido conviene insertar las ordenaciones en el marco general de una política forestal que, desde mediados del siglo XIX, tenía como principales objetivos modificar de manera profunda los derechos de propiedad y de uso de los recursos a fin de potenciar la producción de los montes, de conectarla con los mercados y de garantizar (en mayor o menor grado, según las diferentes medidas adoptadas) la preservación de la riqueza forestal del país.

En ese contexto general, una de las vías más utilizadas para tratar de movilizar la riqueza forestal fue la privatización de montes que quedó institucionalizada con la ley de desamortización de 1855 y que en el largo plazo tuvo una importancia muy considerable al saldarse con la enajenación de un mínimo de cuatro millones y medio de hectáreas ${ }^{7}$. La opción privatizadora presentaba, sin embargo, unos lí-

${ }^{5}$ Las Estadísticas de Producción de los Montes de Utilidad Pública aportan datos básicos sobre la superficie ordenada y sobre la producción de esos montes a escala provincial. Sobre las características de la fuente y su fiabilidad, véase GEHR (1991). Las series elaboradas con esa fuente no incluyen los años forestales 1904/5, 1916/17, 1920/21 y 1930/31, que no han sido localizados.

${ }^{6}$ Los datos sobre la ordenación de los montes de Teruel han sido extraídos de los planes de ordenación y de las memorias de ejecución conservadas en el Fondo Documental del Monte (F.D.M.). Ver FUENTES.

${ }^{7}$ Las cifras de privatización han sido tomadas del GEHR (1994) que calcula la superficie de monte privatizada entre 1859 y 1926 . No obstante, conviene insistir en que se trata de un mínimo ya que esas cifras no contabilizan la privatización de montes que sin duda se produjo 
mites que se manifestaban en varias direcciones. En primer lugar, muchos pueblos titulares de montes opusieron una fuerte resistencia a la venta de sus patrimonios, hasta tal punto que la propia ley de 1855 tuvo que incorporar una serie de motivos de excepción de montes aprovechados de forma comunal ${ }^{8}$. En segundo lugar, los propios técnicos forestales defendieron desde mediados del siglo XIX un ideario que el Ministerio de Fomento acabó haciendo suyo, y que consideraba que la iniciativa privada era incapaz de garantizar la conservación de la riqueza forestal, lo cual aconsejaba que algunos montes -en especial aquellos que eran considerados como «montes protectores» por sus efectos beneficiosos sobre el medio- permanecieran en manos públicas bajo la tutela del Estado ${ }^{9}$. En tercer lugar, la privatización de montes podía implicar un alto coste para los posibles compradores que era resultado no sólo del precio de venta, sino sobre todo del gasto necesario para hacer cumplir los derechos adquiridos - con la necesidad de cercar o establecer vigilancia sobre amplias superficies boscosas- y que, en conjunto, retraía la demanda de este tipo de superficies ${ }^{10}$. En definitiva, la privatización de montes se mostraba, en determinados casos, inoperante y en consecuencia debía ir acompañada de una vía complementaria que implicaba la paulatina formación de un patrimonio forestal público, que con el tiempo alcanzaría más de cinco millones y medio de hectáreas y que el Estado iba a tratar de controlar para cumplir los objetivos perseguidos.

Los montes que por unos u otros motivos fueron quedando en manos públicas -especialmente bajo el control de los ayuntamientos- estaban regulados por normas de carácter comunal, que podían resultar operativas en el marco de una economía tradicional para cubrir determinadas necesidades de ámbito principalmente local o comarcal (pastos, leña para los hogares, madera para construcción rural), pero que no garantizaban una inserción adecuada de la riqueza forestal disponible en el nuevo contexto económico más exigente en materias primas que

en proporciones elevadas durante la primera mitad del siglo XIX y tampoco toma en consideración privatizaciones de hecho, realizadas al margen de la legalidad que pudieron salir a la luz con posterioridad a 1926.

${ }^{8}$ Los trabajos que han abordado este proceso son muy abundantes. El estado de la cuestión al respecto está recogido en Balboa (1999) y Jiménez Blanco (2002).

${ }^{9}$ Aunque no hay ningún trabajo que haya abordado de manera sistemática la relación entre privatizaciones y deforestación, esa fue la queja habitual de los técnicos forestales. Ese cuerpo, surgido tras la creación en 1848 de la Escuela Superior de Ingenieros de Montes, tuvo una influencia considerable en el desarrollo de la política forestal del país. Sus planteamientos sobre la incapacidad de la iniciativa privada para garantizar la conservación de los montes fueron esgrimidos por primera vez en 1855 en el Informe de la Junta Consultiva de Montes, ICONA (1987), y sirvieron como base para que muchos montes fueran exceptuados de las ventas. Un seguimiento de la concreción legal del informe está en Jiménez Blanco (1991).

${ }^{10}$ En conjunto, al menos en lo que se refiere al tercio norte del país, no fueron raros los casos de montes que se intentaron vender pero que finalmente no encontraron comprador. Puede verse al respecto Iriarte Goñi (1996) y Sabio Alcutén (1997). 
se estaba creando ${ }^{11}$. Por eso el Estado intentó arbitrar nuevas reglas de juego que modificaran los mecanismos tradicionales de acceso y que potenciaran un uso más ligado a las necesidades urbanas e industriales, así como una protección a determinados espacios. De entre esas nuevas reglas cabe destacar el establecimiento desde la década de 1860 de unos planes de aprovechamiento forestal que trataban de controlar -normalmente, restringiendo y fiscalizando- los usos vecinales y de fomentar la producción y la comercialización de productos a través de subastas anuales, o la puesta en marcha a partir de 1877 de algunos planes de repoblación. Unos y otros se mantuvieron vigentes durante mucho tiempo e incluso se reforzaron a lo largo del primer tercio del siglo XX, pero constituían formas de actuación muy parciales, que o bien dejaban de lado una planificación de largo plazo que tuviera en cuenta de manera sistemática las mejoras a realizar en los montes -en el caso de los planes de aprovechamiento-, o bien primaban la protección dejando en segundo plano el incremento de la producción -en el caso de las repoblaciones ${ }^{12}$. De ahí que, cuando desde finales del XIX la demanda de materias primas forestales de origen nacional fue aumentando arrastrada por el crecimiento económico y amparada por la protección otorgada desde 1891 a algunos productos forestales, la administración optara por reforzar los cambios impulsando la que en aquel momento podía considerarse como la opción técnica más sofisticada de intervención sobre los bosques, esto es, las ordenaciones ${ }^{13}$.

Técnicamente, los planes de ordenación superaban con mucho a los planes de aprovechamiento o de repoblación ya que trataban de materializar una gestión integral de los espacios forestales. Para ello, siguiendo los dictados de la dasonomía, se pretendía planificar el uso de cada monte o grupo de montes sujetos a ordenación en el largo plazo, incluyendo la extracción de productos que se podía realizar anualmente, las inversiones que debían llevarse a cabo para mejorar la explotación -construcción de casas forestales, de caminos, de vías de saca-y también las repoblacio-

${ }^{11}$ Esta situación, si bien podía dificultar una maximización de la producción forestal no encaja en lo que Hardin (1968) denominó «tragedia de los comunales» ya que no cumplía los dos requisitos que ese autor vincula con dicha tragedia, como son la falta de normas que regularan el acceso -open access- y la sobreexplotación de recursos. De ahí que sea más operativo observar el problema de la gestión comunal analizando las normas concretas que la regulaban. Véase Ostrom (1991) y Hanna y Munasinghe (1995). En el caso de los montes de nuestro país hay ejemplos que demuestran como, en algunos casos, la propia transformación de las regulaciones comunales (sin intervención del Estado) fueron suficientes para fomentar laproducción forestal y conectarla con los mercados. Puede verse al respecto Iriarte Goñi (2001).

${ }^{12}$ Las repoblaciones puestas en marcha hasta la década de los treinta se centraron casi con exclusividad en zonas con fuertes problemas de erosión, es decir se trató de repoblaciones más protectoras que productoras. Un seguimiento de los problemas y los logros de los planes de aprovechamiento en Jiménez Blanco (2002).

${ }^{13}$ Sobre las relaciones entre crecimiento económico y utilización de materias primas forestales y sobre cómo afectó el giro arancelario de 1891 a esos productos véase Iriarte Goñi (2005). Para este último aspecto puede verse también Gallego Martínez (2003). 
nes e intervenciones que debían acometerse para que no se produjera una disminución de los recursos disponibles. Visto desde la actualidad podría decirse que se trataba de un modelo de gestión de recursos naturales renovables que pretendía alcanzar el «rendimiento máximo sostenible» extrayendo cada año una cantidad de productos que igualara el crecimiento medio anual de los mismos, lo cual permitiría obtener un incremento y una regularización de la renta en especie de los montes sin menoscabo del stock inicial existente. Las externalidades positivas de los bosques se tomaban en cuenta sólo de forma cualitativa, considerando implícitamente que una conservación de la masa forestal las garantizaba, pero no se incluían en la contabilidad de costes y beneficios. Por otra parte, el principal interés de los técnicos forestales era incrementar y regularizar la renta en especie, de tal forma que la renta monetaria, como luego se verá, ocupó un lugar que, desde el punto de vista de la Administración, podría considerarse secundario ${ }^{14}$.

Los objetivos técnicos estaban por tanto claros, pero ¿cómo había que afrontaren la práctica los cambios necesarios para acometerlos? La posibilidad de que las entidades titulares realizaran directamente la ordenación extrayendo los productos necesarios, llevándolos a los mercados y reinvirtiendo las ganancias en las mejoras necesarias para garantizar el éxito de las operaciones resultaba poco realista, ya que ni el Estado ni los municipios contaban con los medios ni con la experiencia necesaria para ello. De ahí que la Administración forestal optara desde el principio por implicar en las ordenaciones a empresas privadas que pudieran garantizar una explotación regular, estableciendo acuerdos que modificaban los derechos de uso de los montes y en los que, teóricamente, todas las partes afectadas -las empresas, los municipios titulares y el propio Estado- debían salir beneficiadas. En lo que atañe a las empresas los acuerdos eran, en realidad, contratos de compraventa a largo plazo por los cuales las mismas adquirían materias primas forestales en pie dentro del monte comprometiéndose a pagar un precio predeterminado por unidad de producto y a extraer una cantidad también predeterminada anualmente. Esa renta pagada por los empresarios se destinaba en su mayor parte a los municipios titulares, que obtenían así una compensación por la cesión de derechos que realizaban a las empresas. El resto de la renta -en porcentajes que variaron con el tiempo- iba a parar a manos del Estado que, además de supervisar todo el proceso, se comprometía a utilizar las cantidades que recibía en infraestructuras y repoblaciones que garantizaran el éxito de la ordenación.

${ }^{4}$ Esta forma de gestión quedaba, por tanto, muy lejos de los modelos mucho más sofisticados que la economía de los recursos naturales plantea en la actualidad a través del "control óptimo» o de la "programación dinámica» (véase Reed, 1994a). Algo más adelante, en la década de los veinte, algunos ingenieros forestales españoles plantearon la necesidad de establecer un turno financiero, véase Gómez Mendoza (1992), que encajaría en el tipo que Reed (1994b) describe como «modelo de Faustmann». Sin embargo esa forma de gestión no parece que pasara de los planteamientos teóricos. 


\section{CUADRO 1}

\section{EVOLUCIÓN DE LA SUPERFICIE DE LOS MONTES PÚBLICOS ESPAÑOLES SOMETIDOS A PLANES DE ORDENACIÓN}

\begin{tabular}{|l|r|r|c|r|c|}
\hline & \multicolumn{2}{|c|}{ Ordenado por periodos } & \multicolumn{2}{c|}{ Ordenados acumulados } & Ordenados \\
& \multicolumn{1}{c|}{ (has) } & \multicolumn{1}{c|}{ (has) } & \multicolumn{1}{c|}{ (\%) } & sobre públicos \% \\
\hline $1900-1908$ & 293.485 & 49,9 & 293.485 & 49,9 & 6,0 \\
\hline $1909-1918$ & 134.924 & 23,0 & 428.409 & 72,9 & 8,8 \\
\hline $1919-1924$ & 36.056 & 6,1 & 464.465 & 79,0 & 9,5 \\
\hline $1925-1929$ & 75.472 & 12,8 & 539.937 & 91,8 & 10,8 \\
\hline $1930-1933$ & 47.919 & 8,2 & 587.856 & 100,0 & 11,1 \\
\hline TOTAL (1933) & $\mathbf{5 8 7 . 8 5 6}$ & $\mathbf{1 0 0 , 0}$ & $\mathbf{5 8 7 . 8 5 6}$ & & \\
\hline
\end{tabular}

Fuente: Estadísticas de la Producción de los Montes de Utilidad Pública (1900-1933). Ver nota 5 del texto.

Nota: Ordenados por periodos = hectáreas sometidas a planes de ordenación en cada uno de los periodos cronológicos considerados y porcentaje. Ordenados acum. = hectáreas acumuladas de sujetas a ordenación y su porcentaje. Ordenados sobre total públicos = superficie sujeta a ordenación como porcentaje de la superficie total de montes públicos españoles, excluidos los montes dependientes del Ministerio de Hacienda (susceptibles de enajenación), que posteriormente pasaron a considerarse «montes de libre disposición de los pueblos».

Así pues, en un plano teórico, el tipo de acuerdos parecía estar bien definido. Sin embargo, la concreción de esas normas generales requería unas regulaciones mucho más exhaustivas que eran las que en realidad iban a modelar el proceso. En las secciones posteriores se profundizará en las medidas concretas adoptadas tratando de evaluar sus efectos, pero a modo de presentación el Cuadro 1 muestra el alcance global y el ritmo de las ordenaciones y de él se pueden extraer dos primeras conclusiones. De un lado, pese a que la superficie ordenada tuvo un avance considerable desde 1890 a 1933, abarcando en conjunto más de medio millón y medio de hectáreas, las ordenaciones alcanzaron tan sólo a un 11,1 por cien del total de los montes públicos, lo cual indica que se trataba de una forma de intervención difícil de generalizar, que en la práctica quedó restringida, como más adelante veremos, a los montes con mayores capacidades productivas. De otro lado, hasta el momento sabíamos que la legislación ordenadora estuvo sujeta a numerosos cambios, pero que hasta 1918 las leyes que regulaban estas operaciones fueron muy proclives a los intereses empresariales ${ }^{15}$. Pues bien, si se analiza el

${ }^{15}$ Véase Gómez Mendoza (1992). Las ordenaciones comenzaron a regularse con el R. D. 9 de mayo de 1890 que creaba la Sección de ordenaciones dentro de la Junta Facultativa de Montes. A partir de ahí los cambios más significativos en la ley se produjeron en 1894, 1908, 1918, 1924 y 1929. Las diferentes leyes pueden verse en Sagardoy Zabaleta (1976). La ley de 1918 trató de reforzar el control de la administración sobre el proceso, pero al parecer, frenó la demanda de ordenaciones por parte de las empresas. 
ritmo ordenador tomando en consideración las fechas de los principales cambios en la legislación ordenadora como hace el Cuadro 1, se descubre que casi las tres cuartas partes de las ordenaciones (un 72,9 por cien) se acometieron precisamente en los momentos en los que estaba vigente una normativa favorable a las empresas $^{16}$. Desde esta perspectiva, analizar las regulaciones institucionales arbitradas durante ese periodo de auge ordenador resulta clave para entender los resultados del cambio institucional aquí considerado.

\section{EL PROCESO DE CONCESION A EMPRESAS PARTICULARES}

El éxito de las ordenaciones implicaba necesariamente unas extracciones regulares de materias primas, de tal forma que la opción de vender los productos en pie dentro del monte a empresas interesadas en ellos podría considerarse, al menos en un sentido muy general, adecuada. De hecho, el trabajo de Leffler y Randal (1991) que analiza para la actualidad diversas formas contractuales posibles para la explotación forestal, llega a la conclusión de que, en una situación de alta heterogeneidad de los montes a explotar y con altos costes de medición de las existencias, la venta de los productos en pie trasladando los costes de medición y explotación al comprador, así como la elección de empresarios con experiencia en el sector, son métodos que pueden contribuir a rebajar los costes de transacción y a incrementar la eficiencia. Ahora bien, si nos situamos en el caso español en el primer tercio del siglo XX ¿en qué medida la regulación concreta del proceso de concesión fue adecuada a los objetivos perseguidos? ¿Cómo se eligió a las empresas interesadas? ¿Se potenció la competencia entre ellas antes de otorgarles las concesiones?

Para contestar a estas preguntas y ante la falta de información sistemática para el conjunto del país podemos recurrir a los montes ordenados en la provincia de Teruel para los que se conserva una información abundante sobre el tema. Según se desprende de ese caso, antes de realizar la concesión definitiva a un particular la Administración forestal establecía tres filtros. Se trataba de la concesión de una licencia previa necesaria para poner en marcha los trámites de ordenación e iniciar el proyecto de la misma, de la supervisión de ese proyecto hasta su definitiva aprobación, y de la subasta pública que determinaba quien explotaría el monte a ordenar. El seguimiento diferenciado de cada uno de estos filtros arroja bastante luz sobre la de toma de decisiones y permite un primer acercamiento al grado de eficiencia conseguida a través del proceso de adjudicaciones.

\footnotetext{
${ }^{16}$ El leve repunte de las ordenaciones entre 1924 y 1929 pudo relacionarse con la ley de la Dictadura que permitía realizar ordenaciones bajo la supervisión de los Ayuntamientos y que fue derogada en 1929. Véase al respecto Gómez Mendoza (1992).
} 
Si comenzamos por las licencias previas para iniciar los trámites de ordenación, hay que señalar que las mismas podían ser solicitadas al Ministerio de Fomento por cualquier particular, sin ningún límite explícito en el número de montes o en la superficie. Esas solicitudes eran concedidas por orden de llegada, con la única restricción de que los beneficiarios de las mismas quedaban obligados a presentar un «estudio de reconocimiento» de los montes -no confundir con el proyecto de ordenación propiamente dicho- en un plazo determinado ${ }^{17}$. La sencillez de estos trámites hizo que desde principios de la década de los noventa algunos empresarios relacionados con el sector forestal que no habían podido acceder a determinadas propiedades bien por impedimento legal -montes exceptuados de la desamortización- bien por falta de incentivos económicos -precio de compra y de exclusión elevado respecto a las expectativas de beneficio- solicitaran las licencias para iniciar así los trámites de ordenación e intentar hacerse con la explotación de montes públicos. Sin embargo, la propia sencillez establecida para la adquisición de licencias pudo hacer que el proceso resultara un tanto arbitrario. Así, en el caso de Teruel, dos particulares afincados en Madrid se hicieron en 1903 con las licencias para ordenar respectivamente 46.000 y 17.000 hectáreas que representaban, en conjunto, más de una cuarta parte de los montes públicos de la provincia. La fecha resulta significativa, ya que en 1903 se había inaugurado el ferrocarril que unía Teruel con el Mediterráneo y con Madrid (vía Calatayud) lo cual, al parecer, despertó expectativas sobre el aprovechamiento de los montes de esa provincia. En cualquier caso, los dos beneficiarios iniciales retuvieron las licencias durante varios años sin elaborar los proyectos de ordenación y finalmente las traspasaron a otro particular.

Las conclusiones iniciales que sugiere esta forma de operar son varias. En primer lugar, parece claro que una vez abierta la espita para solicitar licencias, el desarrollo de las ordenaciones dependió de la demanda de los particulares, lo cual suponía implícitamente que sólo se ordenarían aquellos montes que resultaban más atractivos a la iniciativa privada por presentar mejores expectativas de negocio. Dicho de otra forma, las concesiones iniciales estaban hipotecando, de entrada, la capacidad de decisión de la Administración sobre qué montes se ordenaban y sobre qué ritmo se establecía en el proceso globalmente considerado. En segundo lugar, parece que los interesados en las ordenaciones fueron partidarios de acometer esas operaciones en superficies muy extensas, debido a las economías de escala que eso podía suponer. Sin embargo, esa opción de partida dejaba

${ }^{17}$ Entre 1890 y 1896 no hubo una legislación específica sobre la materia, de tal forma que la concesión de licencias tuvo que regirse por los artículos 20 y 21 del reglamento de la Ley General de Obras Públicas de 13 de abril de 1877. Posteriormente, el Real Decreto de 6 de agosto de 1896 en sus artículos $2^{\circ}$ y $3^{\circ}$ concretaba las reglas específicas para conceder a compañías particulares estudios de ordenación. Martínez Alcubillas (dir.), apéndices (1877) y (1896). 
fuera del proceso a pequeños capitales que no podían acometer el coste de ordenar espacios tan amplios, restringiendo de entrada la competencia. En tercer lugar, se percibe también un escaso control sobre los beneficiarios de las licencias que, una vez cumplido el requisito mínimo exigido para su obtención, pudieron retenerlas durante periodos de tiempo no regulados y pudieron organizar en torno a ellas un mercado informal de derechos que restaba transparencia al proceso y que elevaba los costes de transacción ${ }^{18}$. Finalmente, los municipios titulares de los montes a ordenar fueron unos auténticos convidados de piedra, ya que si bien las rentas generadas por la ordenación irían a parar a sus arcas, su capacidad legal para influir en la adjudicación de licencias, simplemente no existía.

Si pasamos al segundo filtro comentado más arriba, es decir, la supervisión de los proyectos de ordenación, conviene empezar señalando que esos proyectos eran en realidad la base técnica de las ordenaciones ya que era a través de su elaboración como se determinaban las existencias del monte, el crecimiento medio anual de las mismas y, en consecuencia, la cantidad de productos que se podían obtener. Los proyectos implicaban, por tanto, una inversión inicial en la realización de esos estudios que la Administración forestal no estaba en condiciones de realizar habida cuenta de sus restricciones presupuestarias ${ }^{19}$. De ahí que el Estado, a través de la legislación, trasladara ese coste a los particulares interesados en explotar los montes, estableciendo que fueran las empresas quienes elaboraran los proyectos ${ }^{20}$. Por otro lado, a los empresarios que quisieran acometer la elaboración de los proyectos se les exigía, además de la licencia, una fianza previa de tantas pesetas como hectáreas tuvieran los montes que pretendían ordenar. Si los particulares estuvieron dispuestos a asumir esas condiciones fue porque, al ser ellos quienes realizaban el proyecto, rebajaban considerablemente el grado de incertidumbre sobre las posibilidades reales que ofrecían los montes, además de poder influir, como luego veremos, en los precios de explotación. El Estado, por su parte, si bien conseguía evitar el gasto del proyecto, no se libraba de afrontar el coste que suponía la supervisión del mismo.

Así las cosas, los empresarios que se embarcaron en la elaboración de proyectos debían contar con una liquidez elevada que les permitiera afrontar los gastos iniciales, además de tener un conocimiento profundo del sector -costes de

\footnotetext{
${ }^{18}$ En Rodríguez (1908) se citan varios casos de transferencias de licencias de derechos de ordenación entre particulares en diferentes provincias, lo que hace pensar que se trató de una práctica habitual.

${ }^{19}$ Aunque ninguna investigación ha analizado los presupuestos forestales, los datos aportados por Comín (1988) respecto a los gastos del Ministerio de Fomento del que dependían las ordenaciones, hace pensar en una fuerte restricción presupuestaria.

${ }^{20}$ La realización de proyectos por parte de los particulares sufrió una pequeña modificación con la ley de 1908 (se introdujo una subasta que determinaba quien los podía realizar) pero sólo en 1918 quedaron en manos de la Administración. Diccionario de la Administración de Alcubillas, apéndices 1908 y 1918.
} 
explotación, mercados, precios de venta- todo lo cual elevaba las barreras de entrada para participar en esas operaciones. Lo ocurrido en Teruel resulta paradigmático si tenemos en cuenta que la persona que finalmente acometió la realización de los proyectos fue Calixto Rodríguez, personaje conocido por sus actividades políticas y empresariales relacionadas con lo forestal. Como político, fue diputado por el Distrito de Molina de Aragón, en Guadalajara -colindante con los montes ordenados de Teruel- durante varias legislaturas y a lo largo de su vida parlamentaria tuvo oportunidad de influir políticamente para facilitar la actividad forestal, tratando de acelerar las concesiones de explotación a particulares y de potenciar ciertas infraestructuras ${ }^{21}$. Como empresario, además de desarrollar diferentes negocios particulares relacionados con los montes, fue el promotor de la Unión Resinera Española, su director desde la creación de esa Compañía hasta 1908 y uno de los principales propulsores de las ordenaciones a escala nacional ${ }^{22}$.

Desde esa posición, en 1906 Calixto Rodríguez adquirió a los promotores originarios todas las licencias concedidas para Teruel, aunque elaboró solamente los proyectos de tres Grupos de montes, que fueron los que en realidad se acabaron ordenando en la provincia. El primero, denominado Grupo de Bronchales, abarcaba 3 montes (7.293 hectáreas) y se dedicaría a la obtención de madera ya que no contaba con árboles de los que se pudiera extraer resina. El segundo y el tercero, denominados respectivamente Grupos de Gea-Albarracín y de Bezas-Tormón, estaban compuestos por 7 montes (16.822 hectáreas), en los que si existía la posibilidad de obtener resina, de tal forma que ese sería el principal objetivo de la ordenación, quedando la explotación maderera como un aprovechamiento importante pero secundario.

En este contexto, el empresario elaboró los proyectos siguiendo las instrucciones marcadas por la ley, sin que la Administración pusiera ninguna objeción a los mismos en la supervisión realizada al efecto. Posteriormente, sin embargo, en el caso de Gea-Albarracín los municipios titulares denunciaron errores importantes en la realización del proyecto que favorecían al concesionario y, después de un pleito largo, el Tribunal Supremo acabó dándoles la razón (Aranzadi, 1930). En qué medida se trató de un mero error técnico o de algo premeditado, es algo que

\footnotetext{
${ }^{21} \mathrm{Al}$ parecer Calixto Rodríguez tenía a gala hablar poco en el Congreso, pero sus escasas intervenciones están estrechamente relacionadas con lo forestal. En 1899 participó varias veces en los debates acusando a Fomento de tardar demasiado tiempo en realizar las concesiones de obras públicas (Diario de sesiones del Congreso, 1899, tomo 81:2641, 84:2752, 101:3368). En 1900 lo hizo en dos ocasiones para favorecer los caminos vecinales (tomo 44:1024) y la guardería forestal (tomo 58:1434). En lo que se refiere a Teruel, en 1900 intervino defendiendo el ferrocarril de Ojos Negros (Teruel) a Vinaroz (tomo 32:890). A partir de 1903 su figura se eclipsa en el Congreso.

${ }^{22}$ Participó en ordenaciones situadas en al menos ocho provincias, según se desprende de sus memorias. Rodríguez (1908).
} 
la documentación disponible no permite aclarar, pero este hecho hace pensar en una escasa eficacia de la Administración para corregir los posibles errores de los proyectos realizados por particulares, quizás porque no podía asumir una supervisión completa que, de realizarse, podía tener un coste bastante similar al de la elaboración del proyecto. Los pleitos sobre cuestiones similares elevados también al Supremo por varios pueblos de la provincia de Segovia cuyos montes habían sido ordenados por particulares, dejan claro que el error cometido en Gea-Albarracín no fue un caso único ${ }^{23}$.

Finalmente, el tercer filtro establecido por la Administración consistía en la celebración de una subasta pública que utilizaba como precios de salida los establecidos en el proyecto aprobado, y que, al menos en teoría, tenía como objetivo facilitar la concurrencia de otros empresarios que pudieran ofrecer unas cantidades superiores para hacerse con la concesión definitiva. Como hemos visto más arriba, los costes de entrada para acometer las ordenaciones eran elevados, de tal forma que la concurrencia no podía ser alta. Pero ¿en qué medida la legislación que regulaba las subastas potenciaba la competencia?

Si retomamos el caso de Teruel, la celebración de las subastas de los distintos Grupos se produjo en fechas bastante distantes y siguió un curso que fue muy diferente. En el Grupo de Bronchales, subastado en 1908, los posibles concurrentes -excepción hecha del elaborador del proyecto- tenían que ingresar previamente en la Caja General de Depósitos una fianza que equivalía al coste del proyecto -incluido un $8 \%$ anual de interés a contar desde el día en que dicho proyecto había sido presentado a Fomento- más un 5\% del valor total de tasación de los productos a explotar. Esa cantidad debía de ingresarse en efectivo y en un solo pago, lo cual, según señalaban algunos expertos exigía una liquidez que daba ventaja adicional a quien había elaborado el proyecto, ya que éste había podido costear el gasto del mismo en pagos aplazados ${ }^{24}$. Si tenemos en cuenta que, por añadidura, el posible licitador debía realizar también un reconocimiento por su cuenta del monte y de sus posibilidades que le permitiera medir la veracidad del proyecto así como hasta dónde podía llegar en las pujas, el coste total para concurrir podía llegar a doblarse. Desde esta óptica, resulta lógico que nadie se presentara a la subasta del Grupo de Bronchales y que Calixto Rodríguez se adjudicara la concesión ${ }^{25}$.

En definitiva, la regulación de las subastas contribuía a elevar los costes de entrada desincentivando con ello las licitaciones. Además, hay alguna evidencia

\footnotetext{
${ }^{23}$ Pleito de la Comunidad de Peguera contra Fomento. Archivo General Administrativo, Justicia, 1346

${ }^{24}$ Fernández de Castro (1908).

${ }^{25}$ Tras obtener la concesión, Calixto Rodríguez la traspaso a su hijo Arturo Rodríguez (F.D.M. Caja 4127) que gestionó la ordenación hasta su fallecimiento en 1924.
} 
de que, en otros casos, se produjeron acuerdos informales entre empresarios para neutralizar la competencia. En este sentido, la declaración del propio Rodríguez resulta meridiana, cuando refiriéndose a una ordenación que él mismo había puesto en marcha en un monte de la provincia de Madrid decía:

«mi intervención con amigos míos que querían concurrir a la subasta dio el resultado de que a la Sociedad [se refiere a la Unión Resinera Española] le fuese adjudicada por el tipo de tasación de 10 céntimos pino. De haber otros licitadores, seguramente no bajaría de 25 céntimos por pino» ${ }^{26}$.

Pese a todo, el marco regulador, si bien daba muchas facilidades a los elaboradores de los proyectos no podía garantizarles la concesión, como podemos comprobar rastreando lo ocurrido con los Grupos de Gea-Albarracín y de Bezas-Tormón. En ambos casos, la subasta definitiva que determinó la concesión no se produjo hasta 1914 y recayó en un empresario diferente, José de Miñón y Garma, que no había tenido nada que ver con la elaboración del proyecto y que además elevó considerablemente los precios de remate. Sin embargo, este hecho no puede achacarse en exclusiva a un incremento de la competencia entre empresarios, sino que respondió a causas bastante más complejas. De hecho, si la concesión tardó siete años en producirse se debió principalmente a la oposición a las ordenaciones que se fue produciendo en la Sierra de Albarracín y que respondía a la profunda modificación en los derechos de uso que suponía el cambio en la gestión de los montes. Ese cambio afectaba a los habitantes más desfavorecidos de los pueblos que hasta ese momento habían utilizado algunos esquilmos forestales como complemento de su exigua renta; pero afectaba sobre todo a los intereses de los grandes ganaderos de la región al dificultar y encarecer el acceso de sus rebaños a los pastos ${ }^{27}$. En este contexto, se iniciaron una serie de maniobras contra la concesión que se desplegaron en varias direcciones. De un lado, en 1911 se consiguió boicotear la subasta pública realizada para determinar quién sería el concesionario; de otro, el asunto se llevó al Congreso de los diputados, dónde el Barón de Velasco, gran propietario de tierra y de ganado afincado en Jaén pero diputado electo por el distrito de Albarracín durante varias legislaturas, presionó al Gobierno para que no realizara la concesión; finalmente, el asunto llegó al Consejo de Estado que paralizó el proceso, de tal forma que la nueva subasta no se produjo hasta $1914^{28}$.

\footnotetext{
${ }^{26}$ Rodríguez (1908, p. 35)

${ }^{27}$ Sobre la situación socioeconómica en la Sierra de Albarracín y sobre los intereses ganaderos de la zona en este periodo, véase Saz Pérez (1999).

${ }^{28}$ Sobre el retraso de la subasta F.D.M. cajas 4134 y 4138 . Las intervenciones en el congreso del Barón de Velasco en Diario de Sesiones del Congreso de los Diputados, 1911 (tomo 461:400402) y 1914 (tomo 489:481-482).
} 
Y fue entonces cuando apareció en escena José de Miñón y Garma, empresario originario de Andujar (Jaén), que desde principios de siglo había creado junto con su hermano Isidoro una Compañía (Miñón Hermanos) que, aparte de regentar una casa de banca fundada en el siglo XIX, operaba y participaba en numerosos sectores industriales tanto en Andalucía como en Madrid, siguiendo una clara estrategia de diversificación que al parecer quiso ampliar instalando una fábrica de resinas en Teruel ${ }^{29}$. Desde esta perspectiva, parece lógico que se interesara por las oportunidades que podía ofrecer la ordenación de los Grupos de Bezas y Gea y que elevara los precios de remate, más si tenemos en cuenta que a la altura de 1914 la actividad resinera podía resultar atractiva debido a la coyuntura que se avecinaba como consecuencia de la Primera Guerra Mundial. De hecho, este fue un momento en el que diversos industriales entraron en el sector al margen de la Unión Resinera Española ${ }^{30}$. Pero lo realmente interesante es la posición en la que este empresario se encontraba respecto al caso de Teruel ya que, como el Barón de Velasco, era un gran propietario de Jaén, lo cual le granjeaba el apoyo del Diputado por Albarracín y, por extensión, de los intereses ganaderos de la Sierra. Podría decirse, por tanto, que José de Miñón y Garma era, en esa situación, un hombre de consenso, y probablemente eso fue tan importante como su capacidad de inversión para hacerse con la concesión de los dos Grupos en 1914.

De lo visto hasta aquí se desprende que si bien la intención de implicar a empresas privadas en la explotación de los montes a ordenar podría considerarse adecuada, los mecanismos concretos a través de los cuales se regularon las concesiones presentaron varios problemas que restaron eficiencia al proceso globalmente considerado. Si bien el marco regulador permitía a la Administración forestal minimizar el coste de elaborar los proyectos, le resto desde el principio capacidad de control dejando algunas de las decisiones más importantes en manos de los empresarios y sin poder garantizar una supervisión eficaz que corrigiera los posibles errores cometidos por los concesionarios. Además, las regulaciones establecidas, lejos de fomentar la libre competencia, contribuyeron a elevar los costes de entrada facilitando que fueran industriales influyentes ya instalados en el sector, o en su defecto, industriales que contaban con contactos políticos, los que accedieran a las ordenaciones. En este sentido, las empresas que participaron en estas operaciones coinciden con lo que ha sido definido como «grupos empresariales» que para reducir los costes de transacción existentes en mercados donde el riesgo y la incertidumbre eran elevados, trataban de conseguir del Estado una regulación favorable a sus intereses ${ }^{31}$. La condición de diputado de Calixto

\footnotetext{
${ }^{29}$ Base de datos REMAN (Registros Empresariales de Andalucía). Agradezco a Josean Garrúes su aportación desinteresada de datos sobre este empresario.

${ }^{30}$ Uriarte Ayo (1994 y 1998).

31 Véase Valdaliso (2002).
} 
Rodríguez y su participación en las comisiones que influyeron sobre el establecimiento de aranceles sobre la resina, o más adelante, la participación de Miñón y Garma en algunas operaciones que trataban de elevar las barreras arancelarias para la madera, parecen atestiguar que su acceso a las ordenaciones podía inscribirse en una estrategia más amplia ${ }^{32}$. Por lo demás, los casos conocidos de otros empresarios que participaron en las ordenaciones en otros ámbitos geográficos, como la Unión Resinera Española (en varias provincias de la Meseta), la empresa El Iratí (en Navarra) u Horacio Echevarrieta (en Huesca), parecen apuntar en la misma dirección ${ }^{33}$.

\section{CONDICIONES Y PRECIOS DE EXPLOTACIÓN}

Una vez conocido el proceso que se siguió para realizar las concesiones a particulares, conviene indagar sobre las condiciones establecidas para la explotación centrándonos en tres aspectos básicos cuyo seguimiento ayuda a aclarar los resultados de las ordenaciones. Se trata del plazo de concesión, de las obligaciones exigidas a los concesionarios y del establecimiento de los precios a pagar por la materia prima extraída de los montes ${ }^{34}$.

En lo que se refiere al primer aspecto, la legislación estipulaba unas concesiones por veinte años. Un plazo que podría considerarse un tanto aleatorio ya que, considerado desde el punto de vista de las coyunturas económicas podría parecer excesivamente largo, pero considerado desde la perspectiva del lento ritmo de crecimiento de los árboles podía ser demasiado corto. En cualquier caso, la Administración forestal se reservaba la posibilidad de variarlo, bien acortándolo si el concesionario incumplía de manera flagrante las estipulaciones del contrato, bien alargándolo con prorrogas de otros veinte años para las que no se establecía ningún límite. Así las cosas, el periodo de concesión daba a los empresarios bastante seguridad habida cuenta de que si seguían interesados en la explotación y se ajustaban a lo marcado en los proyectos, podían obtener un acceso al monte prácticamente indefinido.

\footnotetext{
${ }^{32}$ Véase Reforma Arancelaria (1890). Calixto Rodríguez fue uno de los principales asesores para la resina en la Comisión Arancelaria de 1890. Miñón y Garma era miembro de la Asociación de la Industria Forestal y de la Madera de España y participó activamente en 1924 en las presiones para la subida del arancel de la madera. Saz Pérez (1999)

${ }^{33}$ Sobre las actividades de estas empresas puede verse, respectivamente, Uriarte (1998), Garrúes (1997) y Díaz Morlán (1999).

${ }^{34}$ La información que sigue se ha extraído de los contratos que aparecen en la documentación sobre las ordenaciones de Teruel y de la normativa establecida en las leyes de 1894 (que remite a la ley de obras públicas de 1877) y 1908. Martínez Alcubillas (dir.), apéndices de los años respectivos.
} 
En lo que respecta a las obligaciones de los empresarios las condiciones eran bastante laxas. Lo que se les exigía, básicamente, era que extrajeran anualmente la cantidad de productos marcada en el proyecto que ellos mismos habían elaborado, aunque con un amplio margen de flexibilidad, ya que las previsiones iniciales podían ser alteradas anualmente en las revisiones que hacía la Administración cada año de acuerdo con los representantes de las empresas. Los pagos los realizaban, después de cada campaña, en función de los productos realmente extraídos -no de la superficie explotada- y quedaban eximidos de realizar una reinversión de los beneficios obtenidos en los montes explotados. Obviamente podían realizar obras que facilitaran el aprovechamiento si así lo creían necesario, pero, por ley, la única parte obligada a reinvertir en infraestructuras o repoblaciones era la Administración.

Desde esta perspectiva uno de los elementos fundamentales para determinar los resultados de las ordenaciones era la renta pagada por los empresarios, ya que de ella dependían no sólo los beneficios de las empresas y los ingresos de los municipios titulares de los montes, sino también las posibilidades de inversión de la propia administración. Y esa renta era el resultado, a su vez, de los precios a pagar por unidad de producto extraído que habían sido fijados en los contratos. Merece la pena, por tanto, volver al caso de Teruel y detenerse en este aspecto profundizando sobre el establecimiento de esos precios así como sobre su evolución y sobre los efectos que todo ello pudo generar.

Los criterios seguidos por los elaboradores de los proyectos para calcular los precios de explotación son difíciles de dilucidar para la mayoría de los esquilmos, pero para la madera, y en el caso concreto de Bronchales, existen datos que dan pistas interesantes. En ese Grupo, a la altura de 1906, el precio del metro cúbico se calculó como sigue: primero, se estimó el coste de poner esa cantidad de madera en el principal mercado de destino (Valencia), incluyendo los jornales necesarios y el transporte. A esa cantidad se le añadió un 8\% de riesgo y un 10\% de beneficio empresarial. La cifra resultante se restó del precio que regía en los mercados de venta, y la diferencia fue la que el proyecto estableció como cantidad a pagar por el metro cúbico en el monte ${ }^{35}$. Es de suponer que para el resto de los esquilmos se actuaría de forma similar. Así pues, parece que el establecimiento de precios en los proyectos siguió criterios técnicos y de mercado que no daban a los elaboradores mucho margen de maniobra. Obviamente podían intentar inflar los costes de mano de obra y de transporte para justificar un precio de explotación más reducido, pero hay que tener en cuenta que la Administración revisaba esos criterios y que, además, si los precios propuestos eran muy bajos aumentaba el riesgo de que otro licitador acudiera a la subasta y los elevara. Las posibilidades e incluso los incentivos para establecer unos precios mucho más bajos a los que dictaba la situación real de los mercados en el momento de la elaboración del proyecto parecen ser, por tanto, reducidos.

\footnotetext{
${ }^{35}$ Archivo General Administrativo, Agricultura, 12685.
} 


\section{GRÁFICO 1}

\section{EVOLUCIÓN DE LOS PRECIOS BRITÁNICOS DE IMPORTACIÓN DE ALGUNOS PRODUCTOS FORESTALES. BASE 100=1913 \\ (Libras corrientes)}

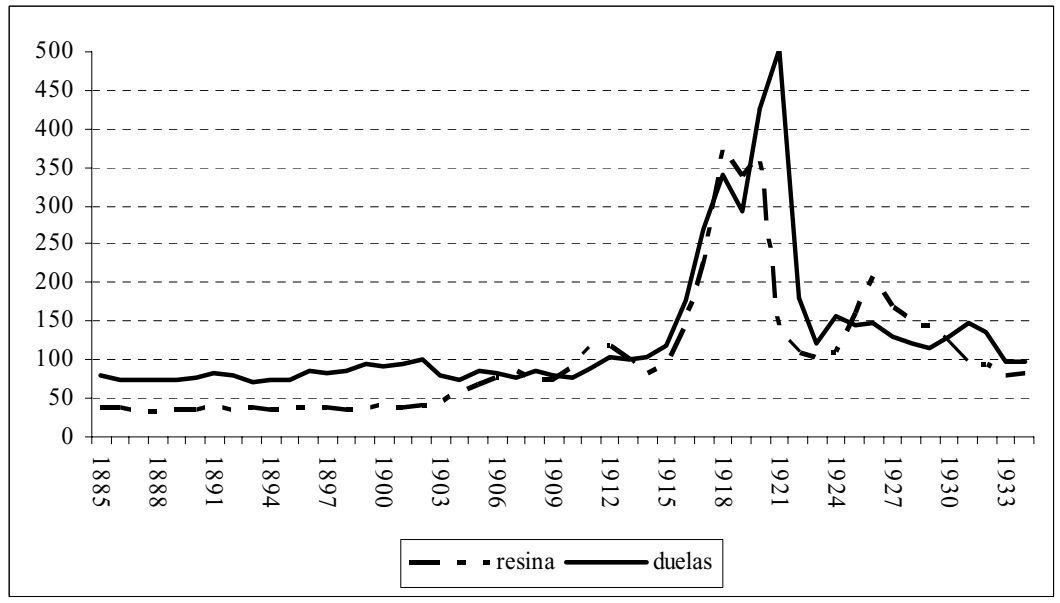

Fuente: Estadísticas del comercio exterior británico.

El elemento más problemático fue, sin embargo, que la legislación determinaba que los precios alcanzados en la subasta de adjudicación se mantendrían fijos a lo largo de toda la concesión, es decir, por veinte años ${ }^{36}$. Esta forma de actuar podría explicarse tomando en consideración la evolución de los precios internacionales de algunos productos forestales significativos (gráfico 1) que habían tenido un comportamiento muy estable desde la década de los ochenta, de tal forma que a la altura de 1894 -año de la ley que regulaba las ordenaciones- no parecía haber motivos para temer un alza de los mismos. Sin embargo, desde finales de la década de los noventa comenzó a extenderse la percepción de que la oferta de productos forestales iba por detrás de la demanda y de que, en consecuencia, los precios de mercado tenderían a incrementarse como señalaban algunos expertos internacionales así como algunos técnicos españoles ${ }^{37}$. Pese a ello,

${ }^{36}$ Como más adelante se especifica, esta norma varió en 1908 estableciendo revisiones quinquenales de precios, pero no se aplicó con carácter retroactivo a las ordenaciones concedidas con anterioridad a esa fecha, independientemente de si las subastas definitivas se habían realizado o no.

${ }^{37}$ Véase Melard (1900) y Revista de Montes (1903). 
la Administración forestal española tardó mucho tiempo en reaccionar -no introdujo las revisiones de precios hasta 1908- y corrigió las cosas de forma muy parcial al no hacer extensiva esa corrección para las ordenaciones cuyos proyectos ya habían sido realizados. Esta forma de actuar podría explicarse, quizás, por criterios técnicos. Teniendo en cuenta que el objetivo de las ordenaciones desde el punto de vista estrictamente forestal era incrementar y regularizar la renta física de los montes logrando extraer una cantidad que igualara el incremento medio anual de las existencias, el mantenimiento de unos precios de explotación constantes daba incentivos a los empresarios para cumplir sus compromisos e ir avanzando en la ordenación. Por contra, una revisión de los precios a corto plazo que obligara a los concesionarios a pagar más por la explotación podía desincentivarlos y dar al traste con el objetivo de regularizar la renta en especie.

En cualquier caso, lo que resulta evidente es que esa opción beneficiaba claramente a los empresarios. Es cierto que existía la posibilidad -si bien muy poco probable por la situación de los mercados internacionales de productos forestales- de que los precios de mercado bajaran, pero de ser así los concesionarios podían renunciar a la explotación sabiendo las pérdidas en las que incurrirían -el coste del proyecto más la fianza depositada. Si por el contrario los precios de venta tendían a subir, las posibilidades de ganancia eran muy superiores. En definitiva, la explotación a precios fijos, si bien mantenía una cierta dosis de riesgo para los empresarios, rebajaba su incertidumbre y abría expectativas de mayores beneficios en el futuro. Como el propio Calixto Rodríguez señalaba, refiriéndose a las condiciones de explotación ofrecidas por las ordenaciones y a los precios futuros esperados para la madera, «difícilmente podrán escogerse circunstancias más favorables para el planteamiento de un negocio»» ${ }^{38}$.

Una aproximación a lo que, partiendo de esta situación, ocurrió en la realidad, puede realizarse a través de los Gráficos 2 y 3. En el primero de ellos se ha construido un índice ponderado de los precios de explotación de los montes ordenados de Teruel que se compara con el índice general de precios y con el índice de precios forestales elaborado para el conjunto de los montes públicos españoles por el Grupo de Estudios de Historia Rural (2002) ${ }^{39}$. En el segundo, se muestra la evolución en números índice de la renta por hectárea ordenada percibida por los pueblos y por el Estado (en pesetas constantes), comparándola con la evolución del índice general de precios, lo cual puede dar una idea tanto del comportamien o de los ingresos generados por las ordenaciones como de la capacidad de compra que cabría atribuir a los mismos.

\footnotetext{
${ }^{38}$ Rodríguez (1908, p. 25).

${ }^{39}$ El índice ponderado para los montes ordenados de Teruel se ha construido siguiendo el mismo método que el GEHR para la construcción de su índice, es decir, se ha dividido la producción total de los montes ordenados de Teruel, valorada a precios corrientes, entre la misma producción valorada en todos los años con los precios de 1913.
} 


\section{GRÁFICO 2}

ÍNDICE GENERAL DE PRECIOS, ÍNDICE DE LAS VALORACIONES MEDIAS DE LOS MONTES PÚBLICOS ESPAÑOLES E ÍNDICE DE LAS VALORACIONES MEDIAS DE LOS MONTES PÚBLICOS DE TERUEL (BASE 100 = 1913)

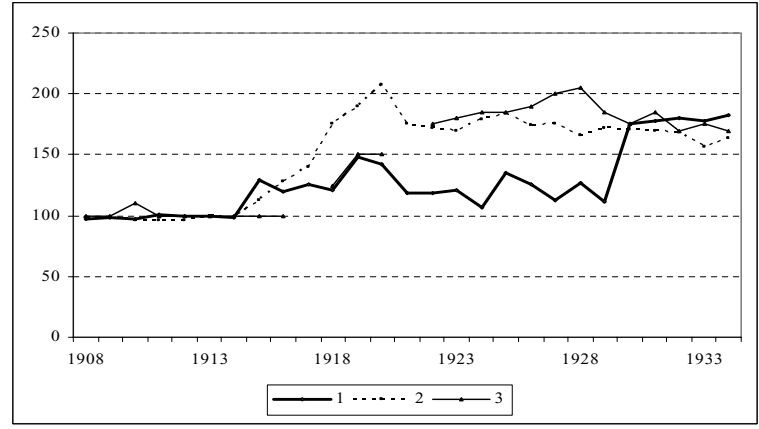

Fuentes: para 1: planes de ordenación y memorias de ejecución de los montes ordenados de Teruel. Ver nota 6 del texto.; para 2: Prados de la Escosura (1995); para 3: GEHR (2002). Notas:

1= Índice de las valoraciones medias de los montes ordenados de Teruel.

2 = Índice general de precios.

3 = Índice de las valoraciones medias de los montes públicos españoles.

\section{GRÁFICO 3}

ÍNDICE GENERAL DE PRECIOS E ÍNDICE DE LA RENTA POR HECTÁREA ORDENADA EN TERUEL PERCIBIDA POR LOS MUNICIPIOS Y EL ESTADO. BASE 100=1913 (Pesetas constantes)

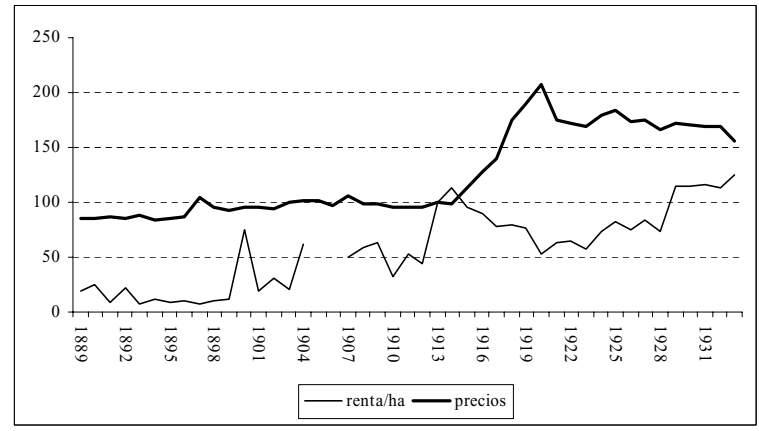

Fuentes: Prados de la Escosura (1995) y planes de ordenación y memorias de ejecución de los montes ordenados de Teruel. Ver nota 6 del texto. 
Y en gran medida nos encontramos con una situación antagónica que permite apreciar una distribución muy desigual de los beneficios monetarios percibidos por las ordenaciones a partir de la Primera Guerra Mundial. De hecho, hasta 1914 las valoraciones de los montes ordenados de Teruel estuvieron en sintonía con las del conjunto de los montes públicos españoles (Gráfico 2), lo cual viene a demostrar que, a la hora de establecer los precios unitarios de explotación, los concesionarios se guiaron por las condiciones generales que regían en los mercados sin que se detecte una infravaloración de los mismos en la elaboración de los proyectos. Esta situación favoreció sin duda a los pueblos y al Estado ya que generó un incremento y una regularización de la renta por hectárea respecto a los años previos a las ordenaciones para los que existen datos (Gráfico 3) que, en un periodo de estabilidad en los precios, debió de ser positiva.

Sin embargo, desde el comienzo de la Gran Guerra las cosas se alteraron sustancialmente. Después de una subida puntual de la valoración de los montes de Teruel en 1915 -que se explica por la entrada en escena de la resinación de los Grupos de Gea y Bezas- con la evolución general de los precios generada a consecuencia de la Primera Guerra Mundial los dos índices forestales crecieron muy por debajo del índice general de precios, lo cual significa que, durante los años de la contienda, se produjo una infravaloración que permitió a los concesionarios de montes públicos (ordenados o no ordenados) apropiarse de una buena parte del valor añadido forestal ${ }^{40}$. Pero fue a partir de 1920 cuando la posición de los empresarios ordenadores comenzó a diferenciarse. De hecho, mientras que las valoraciones del conjunto de los montes públicos tendieron a corregirse ya desde la inmediata posguerra y a situarse incluso por encima del índice general de precios, en los montes ordenados de Teruel esa corrección no se produjo hasta la revisión de precios forzada por los pueblos en 1929 (Gráfico 2). Y esa evolución tuvo para los pueblos y para el Estado justo el efecto contrario, ya que la renta por hectárea, medida en pesetas constantes, tendió a disminuir claramente entre 1916 y 1920 y, aunque a partir de ahí se fue recuperando lentamente no superó el nivel alcanzado en 1913 hasta que se hizo efectiva la citada revisión de precios en 1929 (Gráfico 3).

En definitiva, si tenemos en cuenta que las condiciones de explotación que hemos observado afectaron a todas las ordenaciones que se realizaron en España antes de 1908 (un 49 por cien del total) y a una parte de las que se produjeron entre esa fecha y 1918, podría decirse que la mayor parte de los concesionarios que se hicieron con los derechos de ordenación antes de esa fecha disfrutaron de una situación privilegiada, con unos plazos de concesión que les ofrecían seguridad, unas obligaciones muy laxas que no incluían la exigencia de reinvertir los beneficios en los montes y, sobre todo, unos precios fijos de explotación que

\footnotetext{
${ }^{40}$ GEHR (2002).
} 
combinados con la situación generada por la contienda internacional les permitieron obtener unos beneficios muy elevados por unidad de producto extraído al menos hasta mediados de los años veinte. Como contrapartida, los pueblos titulares de los montes y el propio Estado recibieron una renta que si bien superó a la obtenida antes de las ordenaciones, evolucionó durante un amplio periodo de tiempo muy por debajo del índice general de precios. Y más allá de los problemas de equidad que esa situación pudo plantear, lo más importante para el resultado de las propias ordenaciones fue que, a través de las regulaciones observadas, la propia Administración forestal coarto sus ingresos y coarto, en consecuencia, sus posibilidades de inversión en los montes sujetos a ordenación.

\section{PRODUCCIÓN, PRODUCTIVIDAD Y EFECTOS SOBRE LAS EXISTENCIAS}

Para ir concluyendo este análisis sobre las ordenaciones parece necesario adentrarse en sus resultados productivos, poniéndolos en relación con las normas reguladoras que se han ido rastreando en los apartados anteriores. En este sentido, el Cuadro 2 muestra los porcentajes que los montes ordenados en el conjunto de España fueron alcanzando sobre la superficie, el producto monetario (en pesetas corrientes) y la producción física del conjunto de los montes públicos, y de el se desprenden dos aspectos básicos.

\section{CUADRO 2}

\section{PORCENTAJESDE SUPERFICIE, VALORY PRODUCCIÓN FÍSICADELOS MONTES} ORDENADOS SOBRE EL TOTAL DE LOS PÚBLICOS. MEDIAS ANUALES

\begin{tabular}{|l|c|c|c|c|c|}
\hline & \multirow{2}{*}{ Superficie has. } & \multirow{2}{*}{$\begin{array}{c}\text { Valor } \\
\text { peseta }\end{array}$} & \multicolumn{3}{|c|}{ Valor Producción física } \\
\cline { 4 - 6 } & & $\mathbf{m}^{\mathbf{3}}$ & $\mathbf{k g}$ resina & kg corcho \\
\hline $1900-1908$ & 4,1 & 17,2 & 43,6 & 61,1 & 71,9 \\
\hline $1909-1918$ & 7,9 & 27,2 & 51,1 & 67,3 & 87,9 \\
\hline $1919-1924$ & 9,1 & 26,7 & 60,3 & 65,3 & 70,1 \\
\hline $1925-1929$ & 9,8 & 35,0 & 57,4 & 56,2 & 22,3 \\
\hline $1930-1933$ & 10,9 & 37,3 & 57,2 & 54,3 & 61,8 \\
\hline
\end{tabular}

Fuente: Estadísticas de la Producción de los Montes Utilidad Pública. Ver nota 5 del texto. Superficie has.

Por una parte, como ya habían apuntado algunos trabajos, los porcentajes del producto monetario obtenido de los montes ordenados superaron ampliamente a los alcanzados por la superficie sujeta a ordenación, lo cual parece apuntar a que las ordenaciones contribuyeron a incrementar sustancialmente la productividad 
monetaria de los montes sujetos a esa forma de gestión ${ }^{41}$. Por otra parte, esa idea tiende a reforzarse aún más si consideramos la producción física, ya que los porcentajes alcanzados en las extracciones de madera, de resina y de corcho sobrepasaron con mucho a los que teóricamente cabría esperar en función de la superficie y del producto monetario de los montes ordenados. Esas amplias diferencias, así como su paulatina corrección especialmente a partir de los años veinte, confirman algunos de lo aspectos comentados en el apartado anterior sobre los precios de explotación y sus efectos, pero obligan también a preguntarse a qué se debió la alta producción física de los montes ordenados y cómo fue evolucionando la misma a lo largo del tiempo.

En este sentido, un primer elemento a tener en cuenta para explicar el volumen alcanzado por las extracciones tiene que ver con el tipo de montes sobre el que se desarrollaron las ordenaciones que, en términos generales, presentaban una calidad superior a la media de los montes públicos. El hecho de que, como se ha visto, las ordenaciones se fueran poniendo en marcha en función de la demanda privada, hizo que los montes elegidos fueran aquellos que contaban con unas mejores existencias y con una mayor extensión arbolada por hectárea que podía incluir, además, árboles más desarrollados de los que se podía obtener más cantidad de producto. Estas características quedan perfectamente reflejadas en las Estadísticas de la Producción de los Montes de Utilidad Pública españoles que, en los años para los que ofrecen datos al respecto (1900-1920), contabilizan un porcentaje de superficie arbolada en los espacios ordenados muy superior a la que existía en los montes sujetos a simples planes de aprovechamiento -como media, entre un $80-85 \%$ en los ordenados frente a un $40-45 \%$ en el resto. Así mismo, las informaciones cualitativas de los elaboradores de las estadísticas hacen referencia a este hecho con frecuencia, al explicar los mayores rendimientos de los montes ordenados aludiendo a sus mejores condiciones forestales.

Sobre esa base, el segundo elemento a considerar es de carácter organizativo. El cambio en la gestión acometido con las ordenaciones supuso una explotación sistemática de unos montes que antes se aprovechaban sólo de forma irregular y que se centró muy especialmente en los productos que tenían una mayor conexión con los mercados urbanos e industriales (madera, resina y corcho), relegando a un segundo plano los aprovechamientos de pastos y de leñas más ligados a las economías rurales del entorno. De hecho, observando la composición del producto monetario obtenido de los montes públicos en las fechas para las que existen datos a escala nacional (1911-1920 y 1926-1933), se aprecia claramente como los aprovechamientos de madera, resina y corcho considerados en conjunto representaban antes de la Primera Guerra Mundial en torno a un 75 por cien del total en los montes ordenados, mientras que en los montes sujetos a planes de aprove-

${ }^{41}$ Jiménez Blanco (1991) y para el caso de Aragón, Pinilla (1995). 
chamiento no alcanzaban el 25 por cien. Esta diferencia se fue atenuando considerablemente a lo largo de los años veinte, pero aun así siguió siendo amplia -un 81 por cien en los montes ordenados, frente a un 56 por cien en los de los Distritos entre 1926 y 1933.

Los dos elementos citados ayudan a entender los altos rendimientos físicos obtenidos de los montes ordenados desde principios del siglo XX, especialmente si se ponen en relación con las características propias de la selvicultura. En efecto, uno de los rasgos definidores de la producción forestal es la flexibilidad que la misma ofrece respecto al ritmo de explotación, que al no estar sometido a la caducidad anual del producto -contrariamente a lo que ocurre con la agricultura- puede acelerarse o frenarse en función de diversos estímulos, tanto de mercado como institucionales ${ }^{42}$. Desde esta perspectiva, las reglas establecidas en las ordenaciones -fijación en el proyecto de la cantidad y el tipo de productos a obtener anualmente y estabilidad en la explotación para los empresarios-al aplicarse a unos espacios bien dotados desde el punto de vista forestal, supusieron una fuerte aceleración de las extracciones sin que fuera necesaria una gran inversión más allá de la necesaria para poner en marcha los proyectos. Paralelamente, al tratarse de superficies muy extensas que abarcaban miles de hectáreas, la renovación media anual de las existencias por el mero crecimiento natural de las plantas era elevada, lo cual permitía, al menos en teoría, que la aceleración en las extracciones no disminuyera la riqueza total de cada Grupo ordenado.

Lo ocurrido en Teruel (Cuadro 3) muestra claramente algunos de los extremos que se acaban de apuntar. De hecho, los datos disponibles para los tres Grupos ordenados permiten observar un incremento notable de las extracciones desde el primer año de ordenación, que siguió pautas diferenciadas según el tipo de monte. En Bronchales, dedicado a la obtención de madera, los metros cúbicos extraídos se incrementaron un 67 por cien respecto al periodo previo a la ordenación sin que se perciba un cambio significativo en la composición del producto. En Bezas-Tormón -y muy probablemente también en Gea-Albarracín, aunque no hay datos al respecto- se produjo igualmente un incremento en la extracción de metros cúbicos cercano al 66 por cien, aunque el cambio más importante fue el inició de la explotación resinera que supuso una profunda recomposición del producto en la que los aprovechamientos de pasto y de leña descendieron muy significativamente (del 98 por cien al 10 por cien) ya en el primer año de la ordenación. Pero quizás el hecho más significativo sea que ese importante incremento de las extracciones se produjo en el momento en que la inversión en mejoras por parte del Estado fue más baja (última columna del Cuadro 4). Así pues, parece que el mero cambio en la gestión, unido obviamente a la contratación por parte de los empresarios de mano de obra para desarrollar la explotación, fue suficiente para elevar sustancialmente el producto físico sin que la inversión realizada en mejoras de los montes jugara un papel sustancial en un primer momento.

${ }^{42}$ Puede verse sobre este tema Sala (2003) que pone el énfasis en los estímulos de mercado. También Jiménez Blanco (1999) para los montes corcheros. 


\section{CUADRO 3}

EVOLUCIÓN DE LA PRODUCCIÓN FÍSICA, DE LA COMPOSICIÓN DE LA RENTA MONETARIA Y DE LA INVERSIÓN EN LOS MONTES ORDENADOS DE TERUEL

\begin{tabular}{|c|c|c|c|c|c|c|c|c|}
\hline & \multicolumn{2}{|c|}{ Madera } & \multicolumn{2}{|c|}{ Resina } & \multicolumn{3}{|c|}{ Composición renta ${ }^{a}$} & \multirow{2}{*}{\begin{tabular}{|c|} 
Inversión $^{\mathbf{b}}$ \\
$\begin{array}{c}\% \\
\text { renta })\end{array}$
\end{tabular}} \\
\hline & $\mathbf{m} 3$ & \begin{tabular}{|c|} 
base \\
100 \\
\end{tabular} & $\begin{array}{c}\text { Kg. } \\
\text { Resina }\end{array}$ & $\begin{array}{c}\text { base } \\
100 \\
\end{array}$ & Madera & Resina & $\operatorname{Otros}^{\mathrm{c}}$ & \\
\hline \multicolumn{9}{|l|}{ Bronchales } \\
\hline Antes Ord. & 1.284 & 33 & 0 & & 68,1 & & 31,9 & \\
\hline Primer año & 3.914 & 100 & & & 66,2 & & 33,8 & 13,8 \\
\hline $1908-1913$ & 3.685 & 94 & & & 69,2 & & 30,8 & 13,7 \\
\hline $1914-1920$ & 7.408 & 189 & & & 73,6 & & 26,4 & 23,54 \\
\hline 1921-1924 & 5.257 & 134 & & & 73,6 & & 26,4 & 23,54 \\
\hline \multicolumn{9}{|c|}{ Gea-Albarracín } \\
\hline Antes Ord. & nd & nd & 0 & & nd & nd & nd & nd \\
\hline Primer año & 1.558 & 100 & 865.000 & 100 & 18,1 & 59,9 & 22,0 & 8,9 \\
\hline $1914-1920$ & 6.457 & 414 & 855.564 & 99 & 14,9 & 59,0 & 26,1 & 20,6 \\
\hline 1921-1924 & 8.235 & 529 & 829.542 & 96 & 21,0 & 63,0 & 16,0 & 18,9 \\
\hline $1925-1929$ & 7.842 & 503 & 801.819 & 93 & 18,2 & 55,2 & 26,6 & 14,8 \\
\hline 1930-1933 & 2.523 & 162 & 748.984 & 87 & 4,5 & 82,7 & 12,8 & 15,3 \\
\hline \multicolumn{9}{|c|}{ Bezas-Tormón } \\
\hline Antes Ord. & 204 & 34 & 0 & & 1,9 & 0,0 & 98,1 & nd \\
\hline Primer año & 606 & 100 & 401.038 & 100 & 19,4 & 70,4 & 10,2 & 4,5 \\
\hline $1914-1920$ & 655 & 108 & 477.487 & 119 & 17,4 & 73,4 & 9,1 & 7,4 \\
\hline 1921-1924 & 431 & 71 & 541.407 & 135 & 10,8 & 80,8 & 8,0 & 9,3 \\
\hline $1925-1929$ & 625 & 103 & 508.780 & 127 & 15,0 & 76,9 & 8,8 & 15,1 \\
\hline 1930-1933 & 422 & 70 & 496.572 & 124 & 7,1 & 86,6 & 6,61 & 4,2 \\
\hline
\end{tabular}

Fuentes: Planes de ordenación y memorias de ejecución de los montes ordenados de Teruel. Ver nota 6 del texto.

Notas:

a Porcentajes de la renta total en pesetas obtenidos de cada producto.

b pastos y leñas.

c porcentaje de la renta destinado a mejoras en los montes. 
Sin embargo, otro de los objetivos de las ordenaciones era regularizar las extracciones a lo largo del tiempo, y en ese sentido los datos disponibles señalan algunos problemas importantes. La extracción anual de madera fue incrementándose hasta finales de la Primera Guerra Mundial -hasta 1924 en el caso de GeaAlbarracín- pero a partir de ahí tuvo una tendencia a la baja, y algo similar ocurrió con las extracciones anuales de resina que, pese a su mayor regularidad, también tendieron a descender tras 1924. En líneas generales parece apreciarse, por tanto, un ciclo expansivo hasta principios de los veinte seguido de otro recesivo que no pudo evitarse ni con el reforzamiento de los cambios en la composición del producto que se siguieron produciendo, ni tampoco con la inversión creciente en mejoras que se fue realizando en los montes ordenados de Teruel, que en algunos casos llegaron a representar cifras cercanas a la cuarta parte de la renta total obtenida. Sin embargo ¿̇en qué medida lo ocurrido en esa provincia puede generalizarse al conjunto de los montes ordenados en el país?

Para contestar a esa pregunta se han calculado, para la totalidad de los montes ordenados en España, las tasas de crecimiento medio anual acumulativo de la superficie, de las extracciones físicas de madera y resina y de los rendimientos físicos por hectárea de ambos productos (Cuadro 4), y los resultados aportan datos interesantes. Hasta la Primera Guerra Mundial el incremento medio anual de las extracciones parece explicarse por la ampliación de la superficie ordenada y estaría relacionado, por tanto, con los cambios iniciales en la gestión comentados más arriba. Sin embargo, ya en este primer periodo ese incremento se produjo con rendimientos decrecientes por hectárea respecto al primer año de ordenación, lo cual plantea dudas sobre el incremento real de la productividad más allá de la aceleración en la explotación que supuso la puesta en marcha de los proyectos.

A partir de 1914, sin embargo, la tendencia cambió completamente. El incremento de la superficie ordenada se ralentizó pero el de las extracciones totales sólo disminuyó ligeramente de tal forma que los rendimientos por hectárea crecieron de forma considerable. Los estímulos de mercado generados tanto por la evolución de los precios forestales (Gráfico 1) como por el corte brusco en las posibilidades de importar esos productos, estuvieron sin duda detrás de ese comportamiento durante la Gran Guerra, y pudieron estarlo también en el periodo comprendido entre 1920 y 1924, si tenemos en cuenta que los precios forestales, pese a descender notablemente tras 1920, no volvieron al nivel anterior a la conflagración y que, hasta esa última fecha, no se recuperó en España el volumen de importaciones forestales alcanzado en $1913^{43}$. Por el contrario, desde mediados de los años veinte la recuperación de las importaciones en una coyuntura de caída de los precios forestales internacionales, contribuyó a crear una situación similar en parte a la de preguerra, en la que el incremento de la superficie ordenada -ahora con nuevas

\footnotetext{
${ }^{43}$ Las necesidades de madera para la reconstrucción europea unidas a las profundas alteraciones generadas por la guerra en los mercados especialmente de madera, hicieron que las importaciones forestales no se recuperaran en la inmediata posguerra. Iriarte Goñi (2005).
} 
normas- volvió a crecer -si bien mucho más despacio que en los primeros años del siglo- pero generando un crecimiento modesto de las extracciones que además fue acompañado por una fuerte ralentización en los rendimientos por unidad de superficie -que para la resina se volvieron negativos. Finalmente, la crisis económica general iniciada en 1929 reforzó la tendencia iniciada unos años antes haciendo decrecer tanto las extracciones como los rendimientos.

\section{CUADRO 4}

TASAS DE CRECIMIENTO MEDIO ANUAL ACUMULATIVO

DE LA SUPERFICIE, LA PRODUCCIÓN FÍSICA Y LA PRODUCCIÓN FÍSICA POR HECTÁREA DE LOS MONTES ORDENADOS EN ESPAÑA

\begin{tabular}{|l|c|c|c|c|c|}
\hline & Superficia $^{\mathbf{a}}$ & Madera $^{\mathbf{b}}$ & Resina $^{\mathbf{c}}$ & $\mathbf{\text { m3/ha }}$ & $\mathbf{k g}^{\mathbf{d}} \mathbf{h a}^{\mathbf{e}}$ \\
\hline $1900-1914$ & 10,1 & 6,4 & 6,2 & $-3,4$ & $-3,6$ \\
\hline $1914-1920$ & 0,7 & 4,9 & 4,7 & 4,1 & 3,9 \\
\hline $1920-1924$ & 1,9 & 6,5 & 6,5 & 4,6 & 4,6 \\
\hline $1924-1929$ & 3,8 & 4,2 & 3,6 & 0,4 & 0,2 \\
\hline $1929-1933$ & 2,1 & 0,3 & $-0,8$ & $-0,6$ & $-1,4$ \\
\hline $1900-1933$ & 5,3 & 4,9 & 4,6 & $-0,4$ & $-0,7$ \\
\hline
\end{tabular}

Fuente: Estadísticas de la Producción de los Montes Utilidad Pública. Ver nota 5 del texto.

Notas:

a superficie en hectáreas.

b metros cúbicos de madera extraídos.

c Kilogramos de resina extraídos.

d rendimientos por hectárea de la madera.

e Rendimientos por hectárea de la resina.

En definitiva, a pesar de que las cantidades de madera y de resina a extraer de los montes ordenados venían marcadas, al menos en teoría, por unos proyectos que pretendían regularizarlas a largo plazo, las revisiones anuales que se fueron produciendo -en las que participaban tanto la Administración como representantes de las empresas- tendieron a ajustar las extracciones a los estímulos de mercado olvidando las previsiones iniciales. El crecimiento de los rendimientos por hectárea en aquellos momentos en que los precios eran más remuneradores y su estancamiento o reducción en aquellos otros de precios estables o en descenso así parece atestiguarlo.

Pero la principal consecuencia que puede derivarse de esa evolución hace referencia a los costes de explotación que, por lo que parece, no disminuyeron lo suficiente como para generar un incremento sostenido de los rendimientos por unidad de superficie. En el contexto tecnológico que afectaba al sector forestal a 
finales del siglo XIX y principios XX, la única forma de conseguir ese objetivo era realizar inversiones que mejoraran el acceso a los montes y abarataran la saca de productos, y aunque es evidente que las ordenaciones avanzaron algo en esa dirección, puede decirse que las propias regulaciones ordenadoras trabaron esos avances haciéndolos insuficientes ${ }^{44}$. De hecho, como se ha explicado en el apartado anterior, las normas establecidas no exigían a los concesionarios una reinversión de sus beneficios en los montes, y ello hizo que los empresarios, al menos en el momento de altos beneficios generados por la Gran Guerra, se despreocuparan de los costes de extracción sin acometer mejoras que contribuyeran a reducirlos ${ }^{45}$. Si tenemos en cuenta, además, que los ingresos del Estado procedentes de las ordenaciones evolucionaron muy por debajo del índice general de precios como consecuencia de las regulaciones arbitradas -principalmente por el carácter fijo de los precios de explotación- parece evidente que tampoco la administración pudo invertir unas cantidades suficientes como para rebajar de manera significativa los costes de explotación.

Finalmente, cabría preguntarse sobre los efectos que todo esto tuvo para las existencias de los montes sometidos a ordenación. Y aunque resulta imposible realizar un balance cuantitativo al respecto, algunos datos disponibles permiten intuir que tampoco en este sentido se cumplieron los objetivos. Por una parte, si consideramos que los proyectos que se fueron poniendo en marcha antes de la Primera Guerra Mundial marcaban unas extracciones acordes con el crecimiento medio anual de las existencias, habrá que sospechar que la rápida aceleración de esas extracciones entre 1914 y 1924 pudo suponer una tendencia a la sobreexplotación de los bosques ordenados, que difícilmente pudo frenarse a base de repoblaciones, si tenemos en cuenta los problemas de inversión que se acaban de observar. Sabemos además que la sobreexplotación se produjo en los montes privados, hasta el punto de que la deforestación detectada obligó a que en 1918 el Gobierno estableciera una ley restringiendo la tala indiscriminada de los montes particulares ${ }^{46}$. Desde esta perspectiva, en la medida en que el ritmo de explotación de las ordenaciones se guió por estímulos de mercado parece lógico suponer que también pudo verse afectado por esa tendencia, como ha demostrado Jiménez Blanco (1999), para el caso de los montes ordenados para la extracción corchera ${ }^{47}$.

Pero el problema que pudo alcanzar una magnitud superior fue el relacionado con los usos fraudulentos y los daños causados a los montes en el entorno de las

\footnotetext{
${ }^{44}$ Libecap y Johnson (1979).

45 Baró (1919).

${ }^{46}$ Sobre la ley de prohibición de talas en montes particulares, véase Gómez Mendoza (1992, p. 111).

${ }^{47}$ En el caso del corcho la sobreexplotación se produjo en los años veinte debido principalmente al cambio técnico en la transformación de ese producto (aglomerados del corcho) y a la subida de precios que se derivó de la competencia entre los dos grandes trust internacionales.
} 


\section{CUADRO 5}

\section{DAÑOS CAUSADOS Y USOS FRAUDULENTOS COMETIDOS EN LOS MONTES PÚBLICOS ESPAÑOLES}

(Metros cúbicos por cada 100 hectáreas)

\begin{tabular}{|c|c|c|c|c|}
\hline & \multicolumn{2}{|c|}{ Ordenados } & \multicolumn{2}{c|}{ Distritos } \\
\cline { 2 - 5 } & $\begin{array}{c}\text { Daños m3/ } \\
\text { 100has. }\end{array}$ & $\begin{array}{c}\text { Fraude m3/ } \\
\mathbf{1 0 0} \text { has. }\end{array}$ & $\begin{array}{c}\text { Daños m3/ } \\
\mathbf{1 0 0} \text { has. }\end{array}$ & $\begin{array}{c}\text { Fraude m3/ } \\
\mathbf{1 0 0} \text { has. }\end{array}$ \\
\hline $1900-1908$ & 5,7 & 0,7 & 0,2 & 0,2 \\
\hline $1909-1913$ & 2,5 & 0,3 & 0,3 & 0,1 \\
\hline $1914-1917$ & 2,7 & 0,40, & 40,1 & \\
\hline $1918-1920$ & 7,2 & 0,3 & 0,7 & 0,1 \\
\hline
\end{tabular}

Fuente: Estadísticas de la Producción de los Montes Utilidad Pública. Ver nota 5 del texto. Nota: Los montes de los Distritos eran aquellos montes públicos sometidos a planes anuales de aprovechamiento forestal.

ordenaciones $^{48}$. El hecho de que la mayoría de los proyectos de ordenación se pusieran en marcha sin contar con la opinión de los pueblos titulares generó un fuerte incremento de los usos ilegales, como reconocía la propia Administración en $1908^{49}$. Además, el recorte de los usos vecinales desencadenó toda una serie de reacciones que se podrían englobar bajo el concepto de «protesta delito» y que pudieron causar daños de consideración en los montes, principalmente a través de incendios provocados. En este sentido, los datos disponibles a escala nacional para el periodo comprendido entre 1900 y 1920 que permiten comparar los daños y el fraude que se produjo en los montes ordenados y en los montes sometidos a planes de aprovechamiento resultan reveladores (Cuadro 5). Por una parte, el porcentaje de fraude y sobre todo de daños por unidad de superficie en los montes sujetos a ordenación fue enormemente superior al de los montes de los Distritos. Por otra, si bien es cierto que la capacidad de control del fraude y de los daños en el entorno de los montes ordenados fue bastante alta entre 1908 y 1913, con el comienzo de la Guerra se inició una nueva intensificación primero de los usos fraudulentos y después (en 1917-1918) de los daños, que alcanzaron en ese momento las cotas más altas de todo el periodo considerado ${ }^{50}$. Y, además

${ }^{48}$ Una parte de los daños se debieron a la acción meteorológica (derribos por viento o incendios causados por rayos), pero las cifras son demasiado contundentes como para que puedan ser explicadas simplemente por el azar.

49 «En todos los montes que van a ser sometidos al régimen de ordenación (...) se produce un recrudecimiento intenso en los abusos por cortas fraudulentas», Archivo General Administrativo, Agricultura, 12685.

${ }^{50}$ Sobre la protesta delito y las actuaciones de la Administración forestal para combatirla puede verse GEHR (1999) y GEA (2003). 
de los problemas ambientales que esa situación pudo generar, quizás lo más importante para lo que aquí nos ocupa es que contribuía a generar una inseguridad que incrementaba la incertidumbre de los propios empresarios y les desincentivaba para realizar inversiones en los montes.

\section{A MODO DE CONCLUSION: CAMBIO INSTITUCIONAL Y RESULTADOS PRODUCTIVOS}

Los trabajos que hasta el momento han abordado el tema de la política forestal $\mathrm{y}$ de las ordenaciones para el primer tercio del siglo XX se debaten entre una visión altamente positiva que considera a esas operaciones responsables del incremento de la productividad en el sector forestal y una visión algo más sombría que resalta la utilización interesada de los montes públicos ordenados en provecho de unas pocas empresas privadas. El análisis realizado en las páginas anteriores, centrado principalmente en las ordenaciones que se llevaron a cabo con la legislación anterior a 1918 -un 72,9 por cien del total de las realizadas entre 1890 y 1933- supera ese exiguo estado de la cuestión respondiendo a algunas preguntas clave que permiten valorar en qué medida y con que matices se cumplieron los objetivos perseguidos.

Desde mediados del siglo XIX el Estado español fue estableciendo regulaciones sobre los montes con el doble objetivo de incrementar su producción y conectarla con el mercado al tiempo que intentaba preservar la riqueza forestal del país. En ese contexto y teniendo en cuenta las limitaciones que fue presentando el proceso de privatización institucionalizado en 1855, así como el carácter parcial de las actuaciones forestales que se fueron poniendo en marcha en la segunda mitad del siglo -planes de aprovechamiento y repoblaciones- a la altura de 1890 las ordenaciones constituían una alternativa adecuada. Sobre el papel, su sofisticación técnica para los parámetros de la época, así como el hecho de que intentaran arreglos institucionales que teóricamente beneficiaban a todas las partes interesadas en los montes -municipios titulares, empresas y Administración forestalhacían pensar que esa nueva forma de gestión podía ayudar a cubrir el incremento de la demanda de materias primas forestales de origen nacional sin que eso significara sobre explotar los montes. Sin embargo, las regulaciones concretas que arbitraron los cambios presentaron varios problemas que dificultaron un cumplimiento satisfactorio de los objetivos planteados.

Aunque la opción de implicar a la iniciativa privada en la explotación de los montes públicos debe considerarse positiva por ser la única que podía garantizar una explotación regular de los mismos, la normativa adoptada para realizar las concesiones adoleció de una arbitrariedad inicial que restó a la Administración forestal capacidad de control sobre el proceso globalmente considerado. Además, 
el intento del Estado de minimizar sus costes trasladando la elaboración de los proyectos a los empresarios dejó algunas de las decisiones más importantes en manos de éstos, sin que la Administración forestal pudiera garantizar tampoco una supervisión eficaz. Si a eso añadimos que la normativa, lejos de fomentar la competencia, contribuía a elevar las barreras de entrada, el resultado fue que unos pocos «grupos empresariales» -en el sentido utilizado por Valdaliso (2002)-, habituados a presionar para obtener un marco institucional adecuado a sus fines, se hicieron con las ordenaciones logrando unas condiciones de explotación que si bien resultaban muy favorables para ellos, llegaron a trabar, a medio plazo, algunos de los objetivos de las ordenaciones.

Así, los adjudicatarios consiguieron unos plazos que les daban seguridad en la explotación, una alta flexibilidad en la ejecución que les permitía ajustar las extracciones anuales sin tener que ceñirse estrictamente a los proyectos iniciales y unos precios fijos a pagar por unidad de producto extraído que, combinados con la fuerte inflación generada por la Primera Guerra Mundial, les permitieron obtener enormes beneficios no sólo durante la coyuntura bélica sino también en los años posteriores. Obviamente este hecho tuvo bastante de fortuito porque nadie podía prever antes de la guerra una subida de precios como la que se produjo. Pero lo importante es que ese factor, combinado con unas condiciones que imposibilitaban una corrección adecuada, generó efectos perversos al menos en dos direcciones. Por una parte, la percepción de los municipios titulares de que los beneficios de las ordenaciones se estaban distribuyendo de forma muy desigual generó conflictos -judiciales, sociales y ambientales- que debieron elevar los costes de transacción y crearon una inseguridad que desincentivaba la inversión por parte de unos empresarios que, por lo demás, no estaban obligados por la normativa a reinvertir sus beneficios en los montes. Por otra, los precios fijos de explotación hicieron que la renta obtenida por el Estado evolucionara durante muchos años por debajo del índice general de precios, lo cual implicaba que la Administración forestal estaba perdiendo capacidad de inversión sobre los propios espacios a ordenar.

En este contexto, puede decirse que los objetivos productivos buscados con las ordenaciones se cumplieron sólo parcialmente. Por un lado, es evidente que el cambio en la gestión introdujo importantes transformaciones y consiguió elevar la producción de algunos de los montes mejor dotados desde el punto de vista forestal, contribuyendo a incrementar la disponibilidad de productos en el mercado, sobre todo en un momento en el que las posibilidades de importación estaban mermadas como consecuencia de la Guerra Mundial y de la reconstrucción de posguerra. Sin embargo, ese crecimiento de la producción parece deberse principalmente a una aceleración de las extracciones en aquellos momentos en los que los precios resultaban más remuneradores, sin que nada indique que se produjera un incremento sostenido de la productividad capaz de poner en el mercado cantidades crecientes de materias primas forestales a precios más bajos. Ello hace 
pensar que, como consecuencia de los desajustes en la normativa que hemos observado, las ordenaciones no lograron poner en marcha unas inversiones sobre los montes lo suficientemente elevadas como para rebajar de manera significativa los costes de extracción de productos.

Y algo similar cabría decir del objetivo de preservar las existencias que aunque resulta imposible medir con exactitud, parece que encontró muchas dificultades para cumplirse. De hecho, si las extracciones se guiaron más por los precios de mercado que por las previsiones marcadas inicialmente en los proyectos, y si las propias ordenaciones provocaran conflictos que desembocaron en usos fraudulentos y en daños de consideración a los montes, resulta lógico pensar que en los momentos en los que se aceleró la explotación pudo darse una tendencia a la sobreexplotación. Además, teniendo en cuenta las dificultades inversoras generadas por la normativa, nada garantiza que las labores de repoblación siguieran un ritmo similar al de las extracciones.

En definitiva, el análisis de las ordenaciones muestra la enorme complejidad del cambio institucional y sugiere que a la hora de valorar sus efectos conviene no quedarse en la superficie y profundizar sobre sus posibles derivaciones. Si bien es cierto que la introducción de unas nuevas reglas del juego pudo contribuir a disminuir en ciertos aspectos los costes de transacción estimulando la especialización y el comercio, no lo es menos que la normativa concreta que se aplicó en ese contexto histórico determinado no escogió las reglas más adecuadas y generó efectos no deseados que desvirtuaron los objetivos iniciales, como por lo demás ha ocurrido habitualmente en otros muchas zonas rurales del mundo afectadas por cambios institucionales similares ${ }^{51}$. El análisis sugiere también que, en ocasiones, resulta imposible separar de manera radical los efectos que un determinado cambio institucional tiene sobre la eficiencia de los que tiene sobre la distribución, ya que si las nuevas normas generan ganancias que se reparten de forma muy desigual, puede crear una situación anómala que acaba repercutiendo negativamente sobre la propia eficiencia.

\section{FUENTES}

Fondo Documental del Monte (F.D.M.) Sección Ordenaciones. Cajas 4127, 4128 y 4131 (Grupo de Bronchales) caja, 4138 (Grupo de Gea-Albarracín) y cajas 4134, 4140 y 4147 (Grupo de Bezas-Tormón). Madrid.

Archivo Histórico de la Administración (A.H.N.) Sección Agricultura, caja 12685. Alcala de Henares.

Ministerio de Agricultura Pesca y Alimentación. Estadísticas de la Producción de los Montes de Utilidad Piblica, años 1900-1901, 1901-1902, 1902-1903, 1903-1904, 1905-

${ }^{51}$ Véase Eggertsson (1995), Cernea (1995) y McNeill (2003). 
1906, 1906-1907, 1907-1908, 1908-1909, 1909-1910, 1910-1911, 1911-1912, 1912 1913, 1913-1914, 1914-1915, 1915-1916, 1917-1918, 1918-1919, 1919-1920, 19211922, 1922-1923, 1923-1924, 1924-1925, 1925-1926, 1926-1927, 1927-1928, 1928 1929, 1929-1930, 1931-1932, 1932-1933. Madrid.

\section{BIBLIOGRAFIA}

Aranzadi (1930): Repertorio de jurisprudencia. Pamplona: Aranzadi.

Balboa LÓPez, X. (1999): «La historia de los montes públicos españoles (1812-1936): un balance y algunas propuestas». Historia Agraria 18, pp. 95-128.

BARO, F. (1919): «Los transportes forestales en España: su importancia económica y social». Primer Congreso Nacional de Ingeniería, Sección $8^{\mathrm{a}}$, Industria Forestal y sus derivadas. Madrid: Sucesores de Rivadeneyra, pp. 332-57

Cernea, M. (1995): Primero la gente: variables sociológicas en el desarrollo rural. México: Fondo de Cultura Económica.

Сомín, F. (1988): Hacienda y economía en la España contemporánea (1800-1936). Madrid: Instituto de Estudios Fiscales.

DíAz Morlán, E. (1999): «Propiedad pública y gestión privada: los negocios madereros del empresario Horacio Echevarrieta (1920-1936)». Actas del IX Congreso de Historia Agraria. Bilbao: SEHA, pp. 695-706.

EggerTsSon, T. (1995): El comportamiento económico y las instituciones. Madrid: Alianza.

Fernández de Castro, M. (1908): «Subastas de ordenaciones». Revista de Montes XXXII, p. 253.

Gallego Martínez, D. (2003): «Los aranceles, la política de comercio exterior y la estabilidad de la agricultura española (1870-1914)». Revista de Estudios Agrosociales y Pesqueros 198, pp. 9-74.

Gallego, D. y Pinilla, V. (1996): «Del librecambio matizado al proteccionismo selectivo: el comercio exterior de productos agrarios y alimentos en España entre 1849 y 1935». Revista de Historia Económica XIV (2), pp. 371-420 y XIV (3), pp. 619-39.

GARRUÉs, J. A. (1997): «El IRATI, compañía general de maderas, fuerzas hidráulicas y tranvía eléctrico de Navarra: una empresa autoproductora comercial de electricidad, 1904-1961». Documentos de trabajo Fundación Empresa Pública, número 9701.

GarruÉs, J. A., HernÁndez, S. y MARTín, M. (2003): «Compañías y empresarios de la madera en Andalucía: una aproximación sectorial a partir de las anotaciones registrales», en M.

Martín, J. A. Garrúes y S. Hernández, El registro mercantil: una fuente para la historia económica. Granada: Universidad de Granada, pp. 239-83.

Gómes Mendoza, J. (1992): Ciencia y política de los montes españoles (1848-1936). Madrid: ICONA.

Grupo de Estudios Agrarios (G.E.A.) (2003): «Modos de uso y protesta social en los montes andaluces, 1750-1930. Algunos estudios de caso», en J.A. Sebastián Amarilla y R. Uriarte Ayo (eds.) Historia y economía del bosque en la Europa del Sur (siglos XVIII-XX). Zaragoza: SEHA y PUZ, pp. 161-94.

Grupo de Estudios de Historia RuRAl (GEHR) (1991): Estadísticas históricas de la producción agraria española, 1859-1935. Madrid: MAPA. 
- (1994): «Más allá de la propiedad perfecta. El proceso de privatización de los montes públicos españoles, (1859-1926)». Noticiario de Historia Agraria 8, pp. 99-152.

- (1999): «Diversidad dentro de un orden. Privatización, producción forestal y represión en los montes públicos españoles, 1859-1926». Historia Agraria 18, pp. 129-78.

- (2002): «Política forestal y producción de los montes públicos españoles. Una visión de conjunto, 1861-1933». Revista de Historia Económica XX (3), pp. 509-41.

Hanna, S. y Munsasinghe, M. (1995): Property Rights and the Environment. New York: Beijer International Institute of Ecological Economics, World Bank.

Hardin, G. (1968): «The Tragedy of the Commons». Science 162, pp. 1243-48.

ICONA (1987): Comentarios y Actualidad del Informe de la Junta Consultiva de Montes (Ley 1 de mayo de 1855). Madrid: ICONA.

IRIARTE GoÑI, I. (1996): Bienes comunales y capitalismo agrario en Navarra, 1855-1935. Madrid: MAPA.

- (2001): «Explotación forestal, medio ambiente y derechos de propiedad en los montes municipales de Navarra», en M. González de Molina y J. Martínez Alier (eds.), Naturaleza transformada. Estudios de Historia Ambiental en España. Barcelona: Icaria, pp. 211-38.

- (2005): «La inserción internacional del sector forestal español 1849-1935». Revista de Historia Industrial 27, pp. 11-45.

Jiménez Blanco, J. I. (1991) «Los montes públicos de propiedad pública (1833-1933)». en F. Comín y P. Martín Aceña (dirs.), Historia de la empresa pública en España. Madrid: Espasa Calpe, pp. 241-81.

- (1999): «La oferta de corcho de los montes públicos españoles, 1900-1933», en A. Parejo y A. Sánchez Picón, Economía andaluza e industrialización. Granada: Auskaría Mediterránea, pp. 375-94.

- (2002): «El monte: una atalaya de la historia». Historia Agraria 26, pp. 141-92.

Leffler, K. B. y Randal, R. R. (1991): «Transactions Costs and the Efficient Organization of Producción: A Study of Timber-Harvesting Contracts». Journal of Political Economy 99 (5), pp. 1061-87.

Libecap, G. D. y Johnson, R. N. (1979): «Property Rights, Nineteenth-Century Federal Timber Policy and the Conservation Movement». The Journal of Economic History 39, pp. 129-42.

Melard (1900): «Insuficiencia de la producción de madera en el mundo». Revista de Montes XXIV, pp. 449 y 512.

Martínez Alcubilla, M. (1877, 1896, 1908 y 1918) (dir.): Diccionario de la administración española: compilación de la novísima legislación de España en todos los ramos de la administración pública. Madrid, apéndices.

McNeill, J.R. (2003): Algo nuevo bajo el sol. Historia medioambiental del mundo en el siglo $X X$. Madrid: Alianza.

NADALL, J. (1987): «La industria fabril española en 1900. Una aproximación», en J. Nadal, A. Carreras y C. Sudría (eds.), La economía española en el siglo XX. Una perspectiva histórica. Barcelona: Ariel, pp. 23-61.

Ostrom, E. (1990): Governing the Commons. The Evolution of Institutions for Collective Action. Cambridge: Cambridge University Press.

Pinilla, V. (1995): Entre la inercia y el cambio. El sector agrario aragonés, 1850-1935. Madrid: MAPA. 
Prados de la Escosura, L. (1988): De imperio a nación. Crecimiento y atraso económico en España (1780-1930). Madrid: Alianza.

- (1995): «Spain’s Gross Domestic Product, 1850-1993: Quantitative Conjectures». Universidad Carlos III de Madrid. Working Paper \# 9506.

ReED, W. J. (1994a): «Una introducción a la economía de los recursos naturales y su modelización», en D. Azqueta y A. Ferreiro (eds.), Análisis económico y gestión de los recursos naturales. Madrid: Alianza, pp. 15-32.

- (1994b): «Teoría del control óptimo», en D. Azqueta y A. Ferreiro (eds.), Análisis económico y gestión de los recursos naturales. Madrid: Alianza, pp. 101-17.

Reforma Arancelaria (1890): La reforma arancelaria y los tratados de comercio. Madrid: Sucesores de Rivadeneyra, Tomo 3 Información oral de la comisión, pp. 5 -17

Revista De Montes (1903): «La determinación de los precios en los estudios de ordenación». Revista de Montes XXVII, p. 141.

Rodríguez, C. (1908): En advertencia debida y defensa obligada. Resumen de mi gestión en la Unión Resinera Española. Madrid: Imprenta de José Perales y Martínez.

Sabio Alcuten, A. (1997): Los montes públicos en Huesca (1859-1930). El bosque no se improvisa. Huesca: Instituto de Estudios Altoaragoneses.

SAgarzoy Zabaleta (1976): Resumen por materias de la principales disposiciones sobre legislación forestal, 1833-1976. Madrid: MAPA/ ICONA.

SALA, P. (1997): «Sobre la compatibilitat entre bosc productor y bosc protector. La Catalunya forestal húmida entre la societat agraria y la societat industriaL, 1850-1930». Barcelona: Universitat Autónoma de Barcelona. Tesis doctoral.

— (1998): «Obrador, indústria i aranzels al districte surer catalá (1830-1930)». Recerques 37, pp. 109-36.

- (2003): «Estructura y coyuntura de los precios forestales (maderas, corchos y combustibles en la Cataluña del nordeste, 1850-1930)», en J.A. Sebastián Amarilla y R. Uriarte Ayo (eds.), Historia y economía del bosque en la Europa del Sur (siglos XVIII-XX). Zaragoza: SEHA-PUZ, pp. 257-93.

SANZ FERnÁNDEZ, J. (1986): «La historia contemporánea de los montes públicos españoles. 1812-1930. Notas y reflexiones. II», en R. Garrabou, C. Barciela y J.I. Jiménez Blanco (eds.), Historia agraria de la España Contemporánea. 3. El fin de la agricultura tradicional (1900-1960). Barcelona: Crítica, pp. 142-79.

SAN PÉREz, P. (1999): «La comunidad de Albarracín 1910-1936. El proceso de transformación de una sociedad tradicional». Tesis doctoral. Valencia: Universitat de Valencia.

TAfunelL, X.(1998): «Los beneficios empresariales en España, 1880-1981. Estimación de un índice anual del excedente de la gran empresa». Revista de Historia Económica XVI (3), pp. 707-45.

Tortella, G. (1994): El desarrollo de la España Contemporánea. Historia económica de los siglos XIX y XX. Madrid: Alianza.

Uruiarte Ayo, R. (1994): «La industrialización del bosque en España interior: la industria resinera (1860-1936)». Universidad del País Vasco. Memoria de Cátedra.

- (1998): «Coyuntura económica y estrategia empresarial: La Unión Resinera Española, 1898-1936». Revista de Historia Industrial 14, pp. 83-123

VALDALis0, J. M. (2002): «Grupos empresariales, marco institucional y desarrollo económico en España en el siglo XX: los negocios de la familia Aznar (c.1937-c.1983)». Revista de Historia Económica XX (3), pp. 577-623. 
Zapata Blanco, S. (1986): «El alcornoque y el corcho en España, 1850-1935», en R. Garrabou, C. Barciela y J.I. Jiménez Blanco (eds.), Historia agraria de la España Contemporánea 3. El fin de la agricultura tradicional (1900-1960). Barcelona: Crítica, pp. 230-79.

- (1996): "Corcho extremeño y andaluz, tapones gerundenses». Revista de Historia Industrial 10, pp. 37-67.

- (2001): «La madera en España (c. 1850- c. 1950). Un primer esbozo». Revista de Historia Económica XIX (2), pp. 287-343. 